\title{
The DNA damage checkpoint response to replication stress: A Game of Forks
}

\author{
Rachel Jossen and Rodrigo Bermejo * \\ Instituto de Biología Funcional y Genómica, CSIC/USAL, Salamanca, Spain
}

\section{Edited by:}

Antonio Porro, École Polytechnique

Fédérale de Lausanne, Switzerland

Reviewed by:

Hannah Klein, New York University USA

Giordano Liberi, Istituto di Genetica Molecolare del Consiglio Nazionale delle Ricerche, Italy

*Correspondence:

Rodrigo Bermejo, Genome Integrity Laboratory, Department of Genome Regulation and Dynamics, Instituto de Biología Funcional y Genómica,

CSIC, Universidad de Salamanca,

Calle Zacarías González 2,

Salamanca 37007, Spain.

e-mail: rodrigo.bermejo@usal.es
Conditions challenging replication fork progression, collectively referred to as replication stress, represent a major source of genomic instability and are associated to cancer onset. The replication checkpoint, a specialized branch of the DNA damage checkpoint, monitors fork problems, and triggers a cellular response aimed at preserving genome integrity. Here, we review the mechanisms by which the replication checkpoint monitors and responds to replication stress, focusing on the checkpoint-mediated pathways contributing to protect replication fork integrity. We discuss how cells achieve checkpoint signaling inactivation once replication stress is overcome and how a failure to timely revert checkpoint-mediated changes in cellular physiology might impact on replication dynamics and genome integrity. We also highlight the checkpoint function as an anti-cancer barrier preventing cells malignant transformation following oncogene-induced replication stress.

Keywords: replication forks, DNA damage checkpoint, genomic instability, Mec1/ATR, oncogene stress

\section{INTRODUCTION}

During $S$ phase, cells must faithfully duplicate their genomes. For this purpose eukaryotic cells establish multiple replication forks, specialized structures where DNA synthesis is carried out, that traverse the entire genome in a coordinated manner, thus granting a timely chromosomal replication (Bell and Dutta, 2002). Replication forks are complex structures in which parental DNA is unwound to produce a single-stranded DNA (ssDNA) template for replicative DNA polymerases (Johnson and O'Donnell, 2005). Due to the presence of ssDNA and the necessity to finely tune the functions of the diverse replisome components, replication forks are fragile structures prone to accumulating DNA breaks and being engaged by recombinational repair machineries (Branzei and Foiani, 2010). Conditions that impair DNA synthesis at replication forks or interfere with their progression, collectively termed "replication stress", can alter replication fork structure and functionality thus priming chromosomal breakage and unscheduled recombination events. Recent evidence has suggested that replication stress can be a major source of spontaneous genomic instability driving malignant transformation of pre-cancerous cells (Bartek et al., 2007b).

Eukaryotic cells have evolved mechanisms, usually termed as the replication checkpoint, that monitor the occurrence of replication stress and trigger a cellular response aimed at preserving genome integrity. The replication checkpoint constitutes a specialized branch of the DNA damage checkpoint and it is often referred to as the $\mathrm{S}$ phase (or intra-S phase) checkpoint (Paulovich and Hartwell, 1995; Boddy and Russell, 2001; Nyberg et al., 2002; Osborn et al., 2002). Even if it was originally described as a signal transduction pathway delaying cell cycle progression to provide time to allow replication to finish (Enoch and Nurse, 1990; al-Khodairy and Carr, 1992; Enoch et al., 1992; Rowley et al., 1992; Weinert, 1992), work over the last 25 years has revealed that the replication checkpoint is a complex response with highly interconnected players, which regulates an unprecedented variety of cellular processes in order to sustain cell viability and protect genome integrity (Branzei and Foiani, 2009; Segurado and Tercero, 2009; Zegerman and Diffley, 2009, 2010; Labib and De Piccoli, 2011). Here we will review the current understanding of how the replication checkpoint senses and responds to replication stress, based mainly on the work carried out in the budding yeast model system. We will discuss recent evidence that sheds light on the checkpoint's essential function in promoting replication fork stability and on how cells inactivate checkpoint signaling to restore normal cell physiology. We will also consider the checkpoint from an evolutionary perspective and illustrate how it might act to suppress unrestrained proliferation and tumor progression in multicellular organisms.

\section{REPLICATION FORK STALLING AND CHECKPOINT SIGNALING}

Eukaryotic cells establish multiple replication forks in a timeregulated fashion due to the orderly activation of replication origins throughout $S$ phase (Raghuraman et al., 2001). The Mcm2-7 complex replicative helicase unwinds the parental DNA helix, thus generating a ssDNA template for the replicative polymerases (Waga and Stillman, 1998). RPA stabilizes ssDNA tracks facilitating DNA synthesis and suppressing their engagement by recombination factors (Iftode et al., 1999). DNA polymerase $\varepsilon$ is 
thought to carry out leading strand synthesis, while DNA polymerase $\alpha$ and DNA polymerase $\delta$ primarily synthesize the lagging strand (Pursell et al., 2007). The replication fork is a complex structure in which DNA synthesis is coordinated with other DNA metabolic processes. A number of additional factors associate with replication forks to assist DNA polymerases processivity, lagging strand maturation, topological stress simplification, replisome stabilization, and coordination between replication and sister chromatid cohesion establishment (Tourriere et al., 2005; Gambus et al., 2006; Lengronne et al., 2006; Bermejo et al., 2007; Moldovan et al., 2007).

Faithfull DNA replication requires that replication forks are processive and stable so that DNA synthesis is carried out with high fidelity throughout the genome. Replication fork progression can stall due to different causes. Template unwinding by replicative helicases can be counteracted by topological constraints, higher order DNA structures, or tightly DNA bound proteins (Azvolinsky et al., 2006; Bermejo et al., 2007; Labib and Hodgson, 2007). Additionally, damaged DNA and DNA synthesis inhibition owing to endogenous or exogenous factors may hamper replication fork progression. Agents generating DNA-topoisomerase adducts, intra-strand crosslinks or bulky DNA adducts can block the action of replicative helicases, whilst the progression of DNA polymerases can be impaired by the presence of base-adducts (as the ones generated by methylmethansulphonate-MMS) or by direct inhibition of DNA synthesis (for instance through the depletion of dNTP pools induced by hydroxyurea) (Branzei and Foiani, 2010; Zegerman and Diffley, 2010; Ray Chaudhuri et al., 2012). Replication forks can also interfere with other DNA metabolism machineries. DNA and RNA polymerases compete for the same template during $S$ phase and indeed replication machinery interference with the transcriptional apparatus has emerged as a major cause of fork collapse (for a recent review see Bermejo et al., 2012b). The mechanisms determining replication interference with transcription are not fully understood, though they might implicate clashes between replicative helicases and transcriptional machineries, topological interference with higher order chromatin structures established by co-transcriptional processes [such as gene loops or association with nuclear pore complexes (NPCs)] or engagement of aberrant RNA:DNA hybrids formed by the annealing of nascent RNAs (Deshpande and Newlon, 1996; Azvolinsky et al., 2009; Bermejo et al., 2009; Gomez-Gonzalez et al., 2011; Alzu et al., 2012).

When replication forks stall, a signaling cascade mediated by DNA damage checkpoint kinases is activated, spreading checkpoint signaling to a number of effectors that regulate diverse aspects of cell physiology. Factors involved in sensing and transducing the checkpoint signals generated at replication forks are highly conserved amongst eukaryotes (Table 1). Unless otherwise stated, we will refer in this review to the budding yeast homologs of these factors. At the center of the checkpoint signaling cascade are the phosphoinositide 3-kinases (PI3)-related Mec1 (HsATR) and Tel1 (HsATM) kinases (Weinert et al., 1994; Greenwell et al., 1995; Morrow et al., 1995; Savitsky et al., 1995; Bentley et al., 1996; Mallory and Petes, 2000; Paciotti et al., 2001). Human ATR and ATM are important to suppress malignant transformation
Table 1 | Replication checkpoint sensors and transducers.

\begin{tabular}{llll}
\hline Function & S. cerevisiae & S. pombe & H. sapiens \\
\hline Sensors & Rfa1 & Ssb1 & RPA70 \\
& Rfa2 & Ssb2 & RPA32 \\
& Rfa3 & Ssb3 & RPA14 \\
\hline Apical kinases and & Mec1 & Rad3 & ATR \\
interacting proteins & Tel1 & Tel1 & ATM \\
& Ddc2 & Rad26 & ATRIP \\
\hline Transducers & Mrc1 & Mrc1 & CLASPIN \\
& Rad9 & Crb2 & - \\
\hline Effector kinases & Rad53 & Cds1 & CHK2 \\
& Chk1 & Chk1 & CHK1 \\
& Dun1 & - & - \\
\hline
\end{tabular}

and can be found mutated in cancer cells (Kastan and Bartek, 2004). The highly conserved effector kinases Rad53 and Chk1 are directly targeted by PI3-related kinases and are responsible for the amplification of the checkpoint signal, as well as for the phosphorylation of key proteins that modulate different aspects of cellular physiology (Longhese et al., 2003).

Checkpoint activation in response to replication stress requires the presence of replication forks (Lupardus et al., 2002; Stokes et al., 2002). Indeed, it is thought that the generation of extended ssDNA tracks at replication forks is the main signal triggering replication checkpoint activation (You et al., 2002; Zou and Elledge, 2003). ssDNA at forks can be generated in response to replication inhibitors (such as hydroxyurea or aphidicolin), due to the uncoupling between DNA unwinding by helicases and the progression of DNA polymerases (Sogo et al., 2002; Byun et al., 2005), or by the uncoupling between leading and lagging strand polymerases due to the presence of damaged templates (Branzei and Foiani, 2009). Extended ssDNA tracks are readily coated by the single strand DNA-binding protein RPA complex (composed of Rfa1, Rfa2, and Rfa3) (Zou and Elledge, 2003) (Figure 1A), which recruits the apical kinase Mec1 to stalled forks through the action of its associated factor Ddc2 (Zou and Elledge, 2003). Upon recruitment to fork DNA, Mec1 phosphorylates several factors including Mrcl (Alcasabas et al., 2001; Tanaka and Russell, 2001). Mrcl is a structural component of the replication fork required for both DNA replication and checkpoint signaling (Osborn and Elledge, 2003; Szyjka et al., 2005; Tourriere et al., 2005). In response to replication stress Mrcl acts as a signal transducer mediating full Rad53 kinase activation (Alcasabas et al., 2001). By analogy with the paradigmatic checkpoint transducer $\operatorname{Rad} 9, \mathrm{Mrc1}$ is thought to act as a scaffold promoting Rad53 transautophosphorylation events (Pellicioli and Foiani, 2005; Chen and Zhou, 2009; Berens and Toczyski, 2012). Mec1 phosphorylates Rad53 in a Mrc1-dependent manner, and full kinase activity is achieved when different Rad53 molecules hyperphosphorylate each other before being released to reach their targets (Pellicioli and Foiani, 2005).

$\mathrm{Mrcl}$ is necessary to sustain normal fork progression rates in the absence of genotoxic stimuli (Tourriere et al., 2005). 


\section{A}

RPA-ssDNA

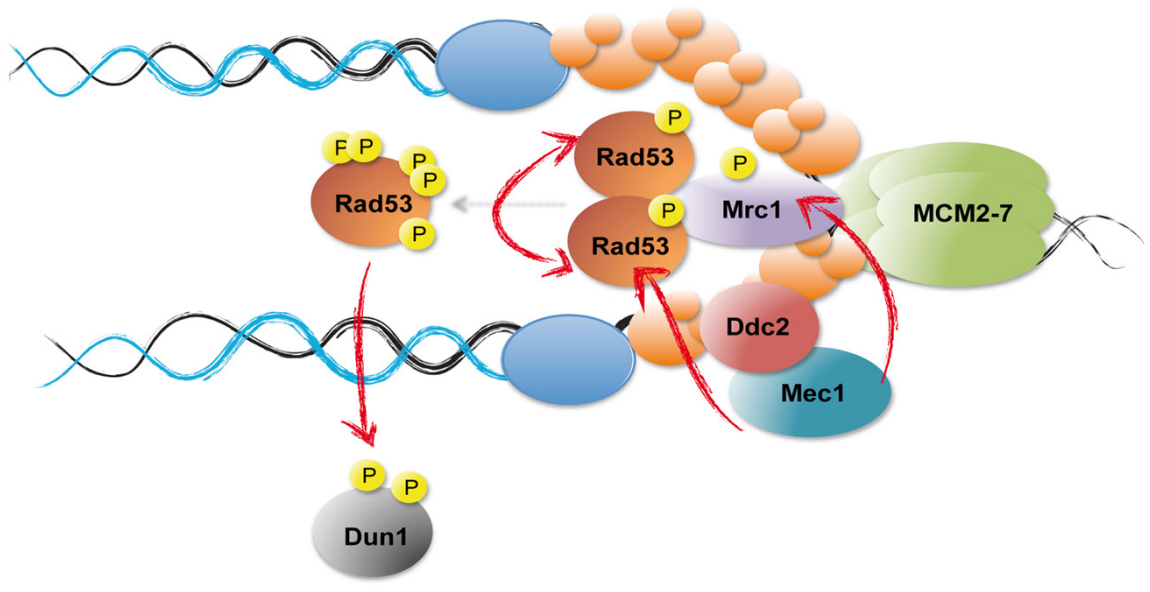

B
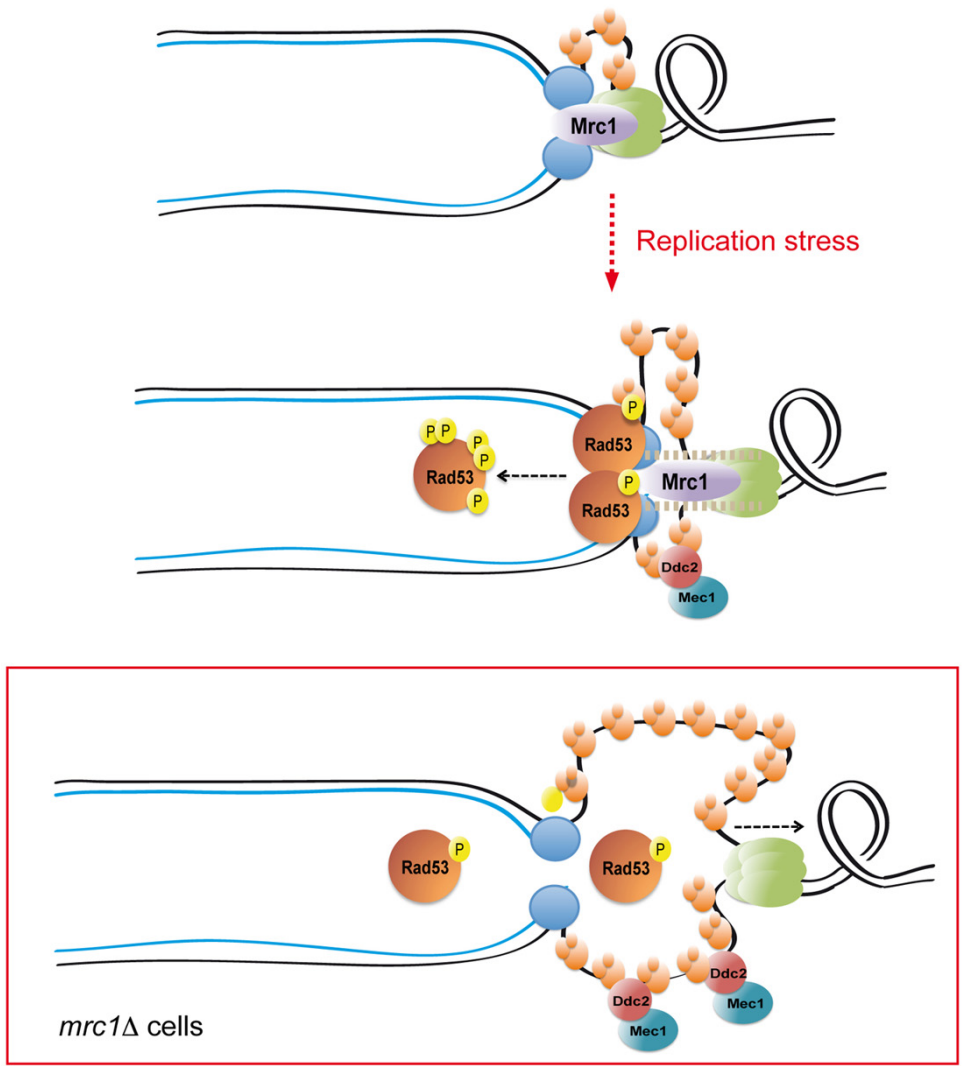

FIGURE 1 | Checkpoint activation in response to replication stress. (A) Upon replication fork stalling ssDNA is generated by the replicative helicase-DNA polymerases uncoupling. RPA-ssDNA mediates the recruitment of the apical checkpoint kinase Mec1 to replication forks by the action of its associated factor Ddc2. Mec1 phosphorylates fork components, including the Mrc1 transducer, and the Rad53 effector kinase. Mrc1 serves as a scaffold promoting Rad53 trans-autophosphorylation events and full kinase activation. Rad53 phosphorylates and activates the Dun1 effector kinase. Red arrows indicate key phosphorylation events mediating checkpoint activation. (B) Mrc1 is a replisome component that travels with replication forks in unperturbed conditions. Following replication stress, Mrc1 prevents excessive DNA unwinding by restraining $\mathrm{Mcm} 2-7$ helicase progression, likely by physically tethering DNA helicases and polymerases. The tension generated between stalled polymerases and advancing helicases may determine conformational changes in Mrc1, thus promoting its function as a molecular scaffold necessary for Rad53 trans-autophosphorylation reactions. In Mrc1 ablated cells ( $m r c 1 \Delta)$, failure to restrain $\mathrm{Mcm} 2-7$ helicase leads to extensive DNA unwinding and ssDNA accumulation at replication forks, which does not directly result in Rad53 hyper-phosphorylation and full kinase activation due to the absence of Mrc1-mediated scaffolding. 
In addition, Mrc1 prevents extensive uncoupling between helicase unwinding and DNA synthesis at stalled forks by somehow tethering helicases to DNA polymerases (Katou et al., 2003; Nedelcheva-Veleva et al., 2006). Importantly, Mrc1 interacts with polymerase $\varepsilon$ catalytic subunit Pol2 in a checkpoint-dependent manner (Lou et al., 2008). Hence Mrcl might act as a "molecular spring" sensing the physical connection between helicases and polymerases and at the same time preventing their uncoupling (Figure 1B). In this view, Mrcl might suppress futile checkpoint signal amplification in forks to which Mecl is recruited to ssDNA but the uncoupling between helicases and polymerases cannot be "physically" sensed.

Modulation of cellular physiology in response to replication stress is ultimately achieved through the regulation of a variety of effectors, which is mediated by phosphorylation events carried out by Mec1, Rad53, and Dun1 kinases (Table 2). Mec1 is thought to act locally by phosphorylating replication forkassociated (Smolka et al., 2007; Randell et al., 2010) and chromatin factors (Randell et al., 2010; Rodriguez and Tsukiyama, 2013). Several Rad53 targets are instead not localized at forks (Smolka et al., 2007; Chen et al., 2010), consistent with the notion that Rad53 may diffuse and propagate checkpoint signaling to distant effectors throughout the nucleus. Recently, the importance of checkpoint-mediated regulation of NPC and nuclear membrane-related processes in genome integrity maintenance has been revealed (Bermejo et al., 2011, 2012a) and it has been proposed that Rad53 might also regulate processes taking place in the cytoplasm (Enserink et al., 2006). Rad53 targets include the Dun1 kinase (Bashkirov et al., 2003), partially related to Rad53 (Zhou and Elledge, 1993; Rhind and Russell, 1998), which promotes the transcriptional induction of damage inducible genes and dNTP pool upregulation. The checkpoint response was originally considered a canonical signal transduction cascade composed by upstream sensors and a number of signal transducer kinases that regulate a large number of downstream effectors (Longhese et al., 2006). The picture though seems far more complex as factors can exert different roles in the cascade. For instance, Mecl acts as a sensor and a signal transducer, but also directly phosphorylates effector proteins. Additionally, several sensors and transducers (as RPA complex proteins, Ddc2, or $\mathrm{Mrc1}$ ) are directly phosphorylated by checkpoint kinases. Below we describe the better-characterized checkpoint-regulated processes contributing to maintain replication fidelity and genome integrity.

\section{CHECKPOINT CONTROL OF S PHASE TRANSCRIPTION AND dNTP POOLS}

The checkpoint response modulates cellular physiology to promote cell survival and preserve genome integrity. One of the earliest described checkpoint functions in response to replication stress is the delay of the progression through mitosis, which is achieved through direct modification of key cell cycle regulators and prevents the premature segregation of incompletely replicated chromosomes (Krishnan et al., 2004; Putnam et al., 2009; Palou et al., 2010). However, the majority of checkpointregulated events relevant for cell viability and genome integrity maintenance are thought to take place in $S$ phase, including
Table 2 | Checkpoint kinases phosphorylation targets overview.

\begin{tabular}{|c|c|c|}
\hline $\begin{array}{l}\text { Checkpoint } \\
\text { kinase }\end{array}$ & Regulated process & Targets \\
\hline \multirow[t]{7}{*}{ Mec1 } & DNA replication & $\begin{array}{l}\text { Cdc2, Dpb4, Mcm4, Pol31, Psf1, } \\
\text { Rfa1, Rfa2 }\end{array}$ \\
\hline & $\begin{array}{l}\text { Checkpoint } \\
\text { response }\end{array}$ & $\begin{array}{l}\text { Ddc2, Dun1, Mec1, Mec3, Mrc1, } \\
\text { Rad9, Rad17, Rad53 }\end{array}$ \\
\hline & DNA repair & $\begin{array}{l}\text { Mlh1, Msh6, Rad23, Rad26, Rad55, } \\
\text { Rtt107, Sae2, Slx4 }\end{array}$ \\
\hline & $\begin{array}{l}\text { dNTP pools } \\
\text { regulation }\end{array}$ & Ssn6 \\
\hline & Chromatin structure & $\begin{array}{l}\text { Abf1, Hta1, les4, Isw2, Sin3, Sir4, } \\
\text { Swi3 }\end{array}$ \\
\hline & NPC function & Hpr1, Nup2, Nup60 \\
\hline & Other & $\begin{array}{l}\text { Cbf1, Cdc13, Nma111, Rif1, Spt7, } \\
\text { Sum1 }\end{array}$ \\
\hline \multirow[t]{7}{*}{ Rad53 } & DNA replication & Sld3, Rad27, Dbf4, Ctf4, Pol1 \\
\hline & $\begin{array}{l}\text { Checkpoint } \\
\text { response }\end{array}$ & $\begin{array}{l}\text { Ddc1, Ddc2, Dun1, Mrc1, Rad9, } \\
\text { Rad53, Tof1 }\end{array}$ \\
\hline & DNA repair & Exo1, Rad54, Rad55, Rtt107 \\
\hline & $\begin{array}{l}\text { dNTP pools } \\
\text { regulation }\end{array}$ & Crt1, Nrm1, Rnr3, Swi6 \\
\hline & Chromatin structure & $\begin{array}{l}\text { Hhf1, Hho1, Hpc2, Esc1, Fun30, } \\
\text { Itc1, Rph1, Snf2 }\end{array}$ \\
\hline & NPC function & $\begin{array}{l}\text { Mlp1, Nsp1, Nup1, Nup2, Nup60, } \\
\text { Hpr1 }\end{array}$ \\
\hline & Other & Mcd1, Plm2, Ycg1 \\
\hline \multirow[t]{6}{*}{ Dun1 } & $\begin{array}{l}\text { Checkpoint } \\
\text { response }\end{array}$ & Dun1 \\
\hline & DNA repair & Nej1 \\
\hline & dNTP pool regulation & Crt1, Dif1, Rnr3, Sml1 \\
\hline & Chromatin structure & Hpc2, Rco1 \\
\hline & NPC function & Mlp1, Nup159 \\
\hline & Other & Ecm21, Npl3, Sec3 \\
\hline
\end{tabular}

upregulation of dNTP pools, inhibition of origin firing, stabilization of replication forks, and modulation of DNA repair. The functional meaning of other checkpoint-mediated effects such as modulation of transfer-RNA (tRNA) genes metabolism (Ghavidel et al., 2007; Nguyen et al., 2010) or the cellular redox state (Carter et al., 2005) are less clear, though repression of tRNA genes might counteract fork collapse by preventing forks clashing with the transcriptional apparatus (Nguyen et al., 2010).

Checkpoint kinases modulate the transcriptional program of cells experiencing replication stress (Smolka et al., 2012). The Dun1 kinase upregulates the transcription of damage inducible 
genes by phosphorylating Crt1 (Huang et al., 1998) (Figure 2A). Crt1 binds to gene promoters and attracts the general transcriptional repressors Ssn6 and Tup1 (Huang et al., 1998). Dun1-dependent phosphorylation displaces Crt1 from promoter chromatin leading to the transcriptional activation of several genes, including DUN1 itself and genes involved in dNTP synthesis, such as the ribonucleotide reductase (RNR) subunits encoding genes RNR3, RNR2, and RNR4 (Zhou and Elledge, 1993; Zaim et al., 2005). Upregulation of DUN1 expression feeds checkpoint signaling, thus contributing to strengthening Dun1-mediated control of dNTP levels (see below).

The MBF (Mlul-box Binding Factor) heterodimeric transcription factor drives the expression of a variety of genes required for G1/S transition (Koch et al., 1993). MBF transcription is repressed upon $S$ phase entry through the binding of the MBF-associated Nrm1 co-repressor (de Bruin et al., 2006). Nrm1 is a phosphorylation target of both Rad53 and its fission yeast ortholog Cds1 (de Bruin et al., 2008; Travesa et al., 2012) (Figure 2A). Rad53-mediated Nrm1 phosphorylation prevents it from binding to the MBF promoters, thus leading to transcriptional upregulation of G1/S transition genes (Travesa et al., 2012). Genes whose expression is upregulated by Rad53 and Nrm1 in response to replication stress encode factors directly involved in DNA synthesis (i.e., RNR1, RFA2, POL1, POL12, $P O L 30, P O L 32, P R I 2$, and DPB2), lagging strand maturation (i.e., $C D C 9$ and $R A D 27)$, replisome components, and accessory factors (i.e., MRC1, CDC45, CTF4, CTF18, ECO1, and ELG1) (Travesa et al., 2012).

The functional meaning of checkpoint-induced transcription is unclear. Preventing protein synthesis by cycloheximide treatment has little impact on cell survival following replication stress (Tercero et al., 2003). This observation led to the suggestion that checkpoint-induced transcription has a relatively small contribution to the stabilization of stalled replication forks. However, Nrm1 ablation confers resistance to hydroxyurea treatment (de Bruin et al., 2006, 2008) and Crtl deletion mutants show increased viability following HU or MMS exposure (Shen et al., 2007 and our unpublished observations). Hence the transcriptional upregulation of key factors might be important to promote cell viability, perhaps by contributing to the

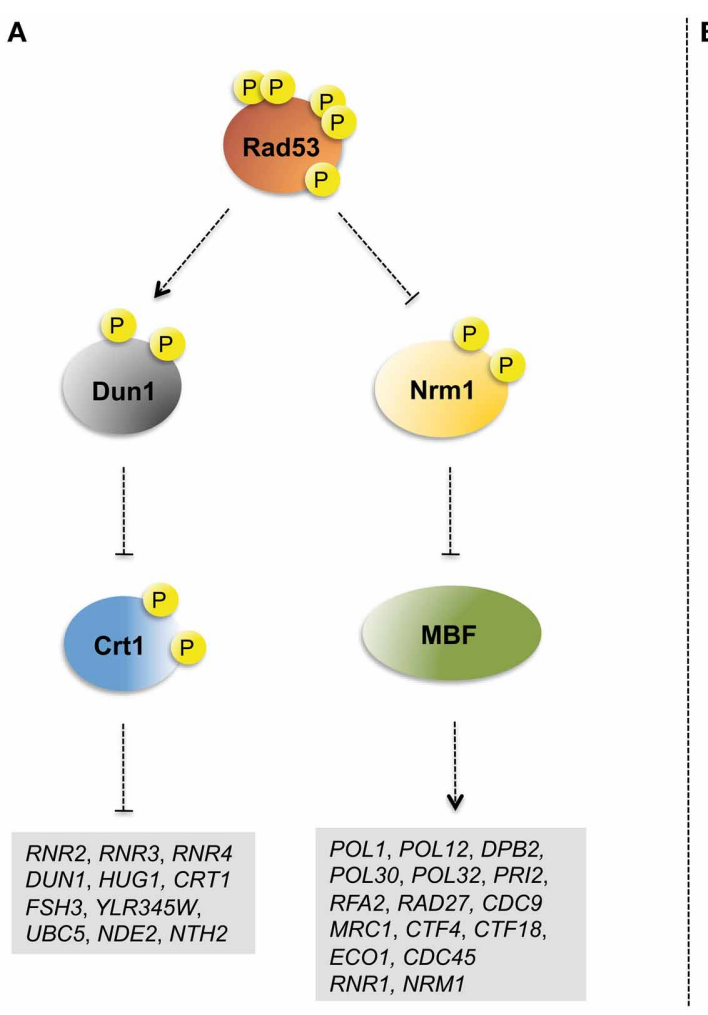

FIGURE 2 | Checkpoint control of $\mathbf{S}$ phase transcription and dNTP pools. (A) Rad53 kinase controls the transcriptional activation of Crt1-repressed damage-inducible and G1/S transition MBF genes in response to replication stress. The transcriptional repressor Crt1 is phosphorylated in a Rad53- and Dun1-dependent manner and displaced from the promoters of damage-inducible genes. Rad53 also phosphorylates the MBF-specific repressor Nrm1 allowing the expression of G1/S transition genes. Relevant genes with roles including dNTP pool regulation, checkpoint response, DNA replication, and DNA repair that are induced following replication stress in a checkpoint-dependent manner are listed.

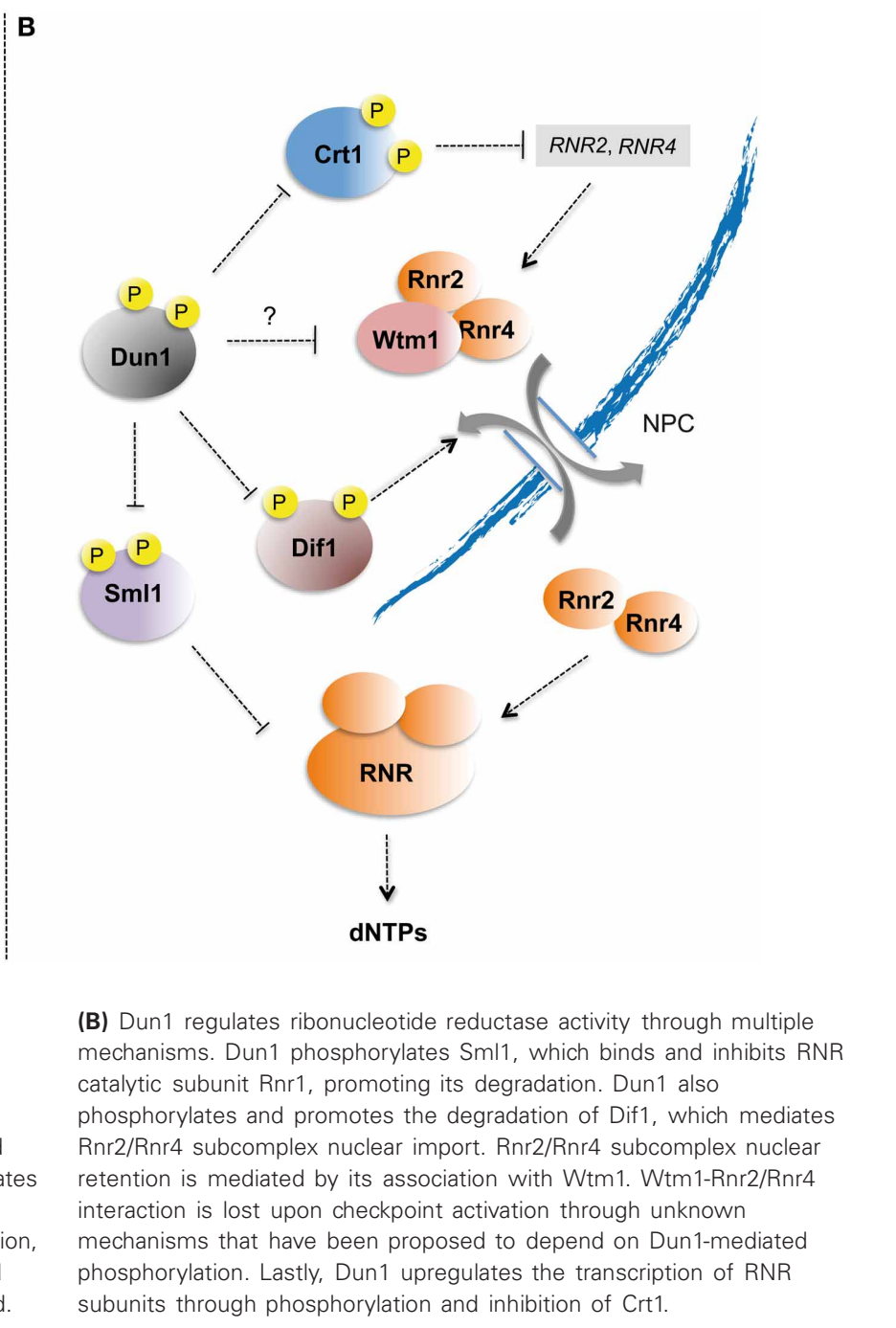


stabilization of replication forks or the upregulation of dNTP levels. Further investigation will be required to elucidate this intriguing connection.

Tight regulation of dNTP pools is essential for cells to guarantee viability and prevent elevated mutagenesis rates (Chabes et al., 2003). Deregulation of the dNTP pool leads to genomic instability in yeast (Zhao et al., 2001) and mammalian cells (Bester et al., 2011). The replication checkpoint upregulates dNTP levels in response to replication stress, mainly through modulation of RNR activity (Figure 2B). RNR is a multimeric enzyme that catalyzes the reduction of ribonucleotides to deoxyribonucleotides, the rate-limiting step in $\mathrm{dNTP}$ synthesis. During most of the cell cycle the large catalytic subunit Rnr1 localizes to the cytoplasm, while Rnr2-Rnr4 subcomplex is nuclear (Yao et al., 2003). Dif1 directly binds and mediates the nuclear import of the Rnr2Rnr4 subcomplex (Lee et al., 2008), which is retained in the nucleus through the action of Wtm1 (Lee and Elledge, 2006). Activation of checkpoint kinases leads to the re-localization of the RNR small subunits Rnr2-Rnr4 from the nucleus to the cytoplasm (Lee and Elledge, 2006). Following replication stress Dun1 phosphorylates Dif1 inducing its degradation (Lee et al., 2008) and Wtm1 interaction with the Rnr2-Rnr4 complex is abrogated (Lee and Elledge, 2006). Redistribution of Rnr2-Rnr4 to the cytoplasm favors its association with Rnrl to constitute an active RNR complex and upregulate dNTP levels. As mentioned above, RNR subunits are transcriptionally induced in response to replication stress. A more striking effect is observed for $R N R 3$. Rnr3 is an alternative catalytic subunit that can substitute Rnrl to form active RNR complexes (Domkin et al., 2002) targeted by Rad53 (Smolka et al., 2007). RNR3 has very low expression levels in the absence of genotoxic stresses and its protein levels following replication stress are relatively low as compared to those of Rnr1 (Li and Reese, 2001; Domkin et al., 2002). Hence, the functional role of Rnr3 in dNTP pool regulation remains unclear.

Checkpoint kinases also upregulate dNTP levels through Sml1, a small protein that directly binds to Rnrl and inhibits RNR enzymatic activity (Zhao et al., 1998; Chabes et al., 1999). Phosphorylation of Sml1 by Dun 1 triggers Sml1 degradation via a complex formed by the E2 ubiquitin-conjugating enzyme Rad6, the E3 ubiquitin ligase Ubr2, and the accessory factor Mub1 (Zhao and Rothstein, 2002; Andreson et al., 2010). Upregulation of dNTP pools could contribute to stabilizing replication forks by directly increasing polymerase processivity or by facilitating a more efficient repair of lesions blocking fork progression. Importantly, Mec1 and Rad53 are thought to regulate dNTP pools in unperturbed $\mathrm{S}$ phase, as the lethality of MEC1 or RAD53 deletion is suppressed by Sml1 ablation (Zhao et al., 1998), and defective dNTP pool regulation in checkpoint mutants results in spontaneous fragility of hard-to-replicate genomic regions (Cha and Kleckner, 2002).

\section{CHECKPOINT CONTROL OF REPLICON DYNAMICS AND FORK STABILITY}

Cells experiencing replication stress modulate chromosomal replication through at least two checkpoint-dependent mechanisms: the stabilization of stalled replication forks and the block of origin firing. Replication origins fire with a somewhat pre-defined timing throughout unperturbed S phases (Raghuraman et al., 2001). In response to replication stress origin firing is regulated by checkpoint kinases that mediate the repression of late and dormant origins (Santocanale and Diffley, 1998; Shirahige et al., 1998). This effect is directly mediated by Rad53, which phosphorylates Dbf4 and Sld3 proteins thus short-circuiting the two alternative Dbf4-dependent kinase (DDK) and cyclin-dependent kinase $(\mathrm{CDK})$ pathways that promote origin firing in $\mathrm{S}$ phase (Lopez-Mosqueda et al., 2010; Zegerman and Diffley, 2010). Interestingly, dormant origin derepression also takes place when a double strand break (DSB) is induced at a neighboring HOendonuclease sequence in the budding yeast mating type locus (Doksani et al., 2009). HO-break mediated origin derepression occurs even when Rad53 is fully activated owing to HU treatment. Hence alternative mechanisms, perhaps involving chromatin structure changes, might bypass checkpoint control on origin firing. Prevention of late origin firing in response to replication stress seems to have obvious advantages for the cell. When forks stall due to reduced dNTP levels, establishing more replication forks at late origins would further increase dNTPs demand. In the presence of damaged templates, limiting late origin firing would prevent additional forks to stall by running into DNA lesions. However, the inability to prevent late origin firing is not thought to be the major cause of cell lethality in checkpoint mutants experiencing replication stress as mec1-100 mutants, which fail to prevent late origin firing, are not sensitive to $\mathrm{HU}$ or MMS treatments (Tercero et al., 2003).

The most crucial function exerted by checkpoint kinases is the protection of fork stability (Lopes et al., 2001; Tercero and Diffley, 2001; Sogo et al., 2002), which has been argued to account for the maintenance of cell viability following replication stress (Segurado and Diffley, 2008). In checkpoint mutants, replication forks fail to resume DNA synthesis after removal of replication stress-inducing drugs (Desany et al., 1998) and accumulate DNA breaks (Feng et al., 2006; Raveendranathan et al., 2006; Feng et al., 2011). The loss of replication fork functional integrity accompanied by structural alterations of replication intermediates is usually termed fork collapse and it is thought to be a major cause of gross chromosomal rearrangements in checkpoint-deficient cells (Myung et al., 2001; Myung and Kolodner, 2002; Admire et al., 2006). Fork stability defects also result in an increased incidence of malignant tumors (Kawabata et al., 2011). Currently the checkpoint-mediated mechanisms counteracting fork collapse are not fully understood, though fork-protecting pathways may interplay.

Collapsed replication forks in checkpoint deficient cells are characterized by the accumulation of abnormal replication intermediates (Lopes et al., 2001; Cotta-Ramusino et al., 2005). Prominently, checkpoint mutants exhibit forks in which nascent strands re-anneal to generate four-way junctions, often referred to as reversed forks (Sogo et al., 2002). Formation of reversed forks is promoted by the accumulation of torsional stress both in vitro and in vivo (Postow et al., 2001a,b; Bermejo et al., 2011; Ray Chaudhuri et al., 2012). Positive supercoiling generated by DNA unwinding at the replication fork tends to re-anneal parental DNA strands (Wang, 2002), thus regressing the fork branching point, and strip-off the nascent strands. Nascent strands can 
in turn pair due to their sequence homology (Figure 3A). Fork reversal driven by positive supercoiling is favored in vitro by protease treatments that eliminate replisome components from fork DNA, suggesting that the association of replisome factors with nascent DNA strands might counteract the topological transitions leading to fork reversal (Postow et al., 2001b). Recent evidence suggests that the replication checkpoint modulates chromosome architecture and can attenuate the impact of positive supercoiling on stalled forks (Bermejo et al., 2011; Dion et al., 2012; Mine-Hattab and Rothstein, 2012). Rad53 phosphorylates the
Mlp1 nucleoporin, which mediates the association of RNA polymerase II transcribed genes to NPCs in a phenomenon known as gene gating (Kohler and Hurt, 2007). Transcribed chromatin associating with the fixed NPC structure would prevent the rotation of DNA strands around each other establishing a barrier to the diffusion of topological changes (Koster et al., 2010). In this view, positive supercoiling would tend to progressively accumulate as replication forks approach transcribed genes (Figure 3B). Upon treatment with $\mathrm{HU}$, transcribed genes association with NPCs is released in a checkpoint-dependent manner (Bermejo

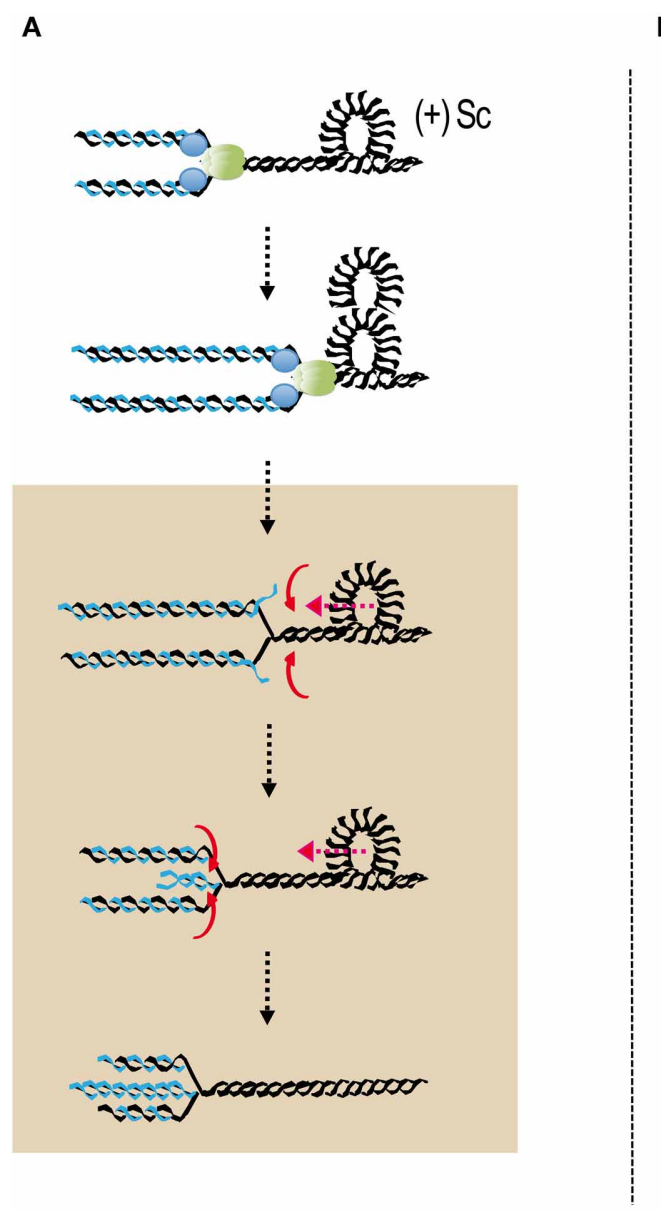

FIGURE 3 | Replication fork reversal and checkpoint-mediated topological simplification at transcribed regions. (A) DNA double helix unwinding during replication generates torsional stress that can accommodate as positive supercoiling $(+\mathrm{Sc})$ ahead of replication forks. Progressively accumulating positive supercoiling provides the driving force for replication fork reversal; particularly upon the dissociation of replisome components from fork DNA. Positive supercoiling can be re-accommodated by re-winding of the parental strands, which results in the regression of the fork branching point and the extrusion of newly synthesized strands (in blue). Newly synthesized DNA strands annealing, driven by sequence homology, leads to the formation of four-way cruciform junctions known as reversed forks or chicken feet. Reversed forks can branch-migrate due to further positive supercoiling-driven parental strand re-annealing. Replisome components are represented as green and blue circles. The gray box

delimits aberrant transitions leading to fork reversal. (B) Activation of
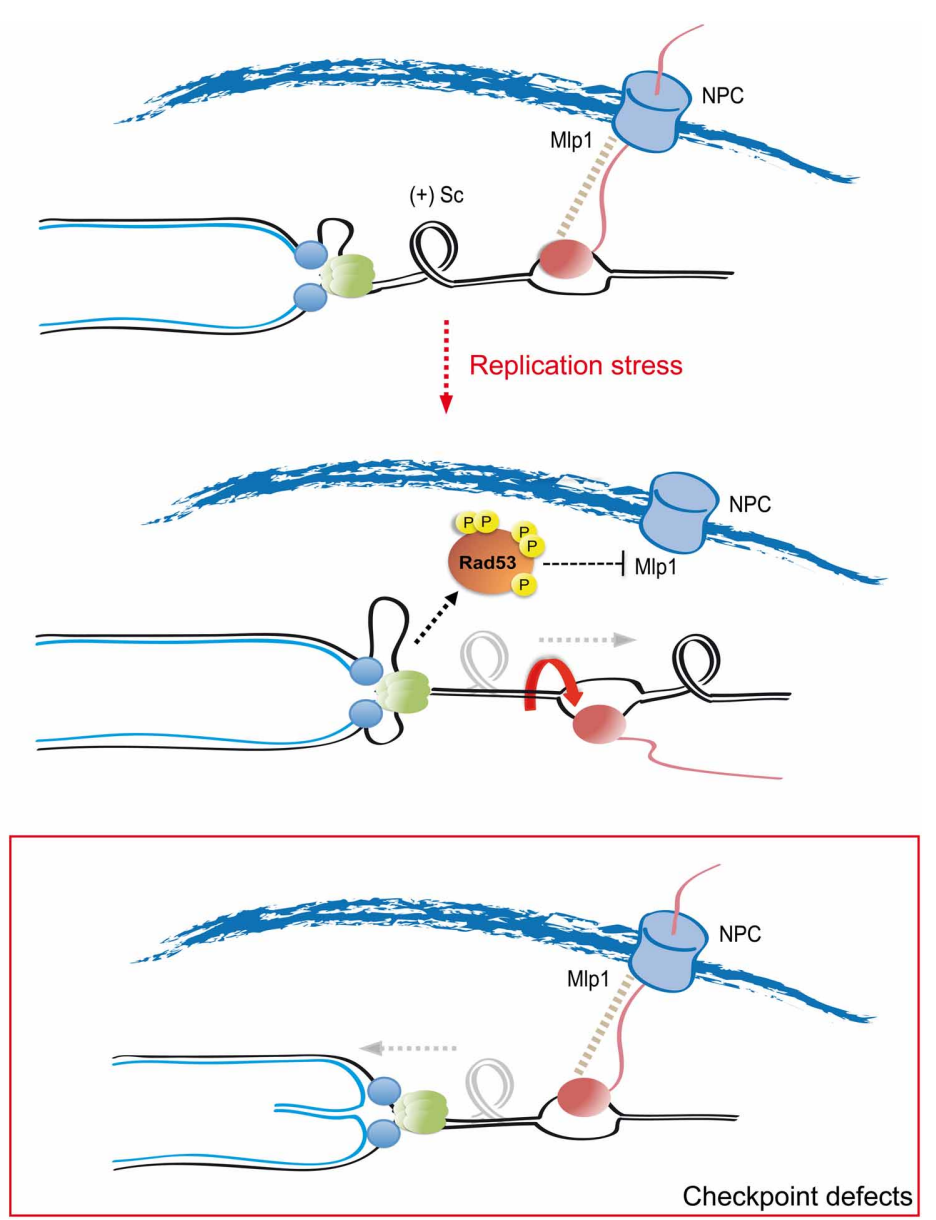

Checkpoint defects checkpoint kinases counteracts gene gating. In S phase, replication forks engage RNA polymerase II-transcribed genes, which associate to the inner basket of NPCs through the action of co-transcriptional protein complexes and key nucleoporins (including Mlp1) in a process known as "gene gating." Gated genes behave as barriers to topological stress diffusion as they counteract the rotation of helix strands around each other, thus favoring the accumulation of positive supercoiling ahead of approaching replication forks. Following replication stress Rad53 phosphorylates Mlp1 thus releasing transcribed genes from their association to the nuclear pores. Disengagement of transcribed genes permits DNA rotation and the diffusion of topological stress away from replication forks. In checkpoint deficient cells topological barriers persist, favoring positive supercoiling relaxation through reversal of stalled forks. Replisome components and the transcriptional apparatus are represented as green/blue and pink circles, respectively. 
et al., 2011), likely removing topological barriers that drive local positive supercoiling accumulation and promote fork reversal (Figure 3B). Reversed forks cannot sustain DNA synthesis and might represent a terminal step of fork stalling accounting for the loss of viability of checkpoint mutants upon treatment with replication stress inducing drugs. Genetic contexts suppressing fork reversal positively affect checkpoint deficient cells survival upon HU treatment (Bermejo et al., 2011) and mechanisms re-starting reversed forks in the absence of checkpoint kinases have not been described. It is, however, unclear whether fork reversal is necessarily a terminal event in eukaryotic cells (Ray Chaudhuri et al., 2012).

Nucleolytic processing activities also engage collapsed replication forks. Checkpoint mutants experiencing replication stress induced by dNTP pool depletion accumulate forks with extended ssDNA gaps and replication bubbles in which one of the nascent strands is absent (Sogo et al., 2002). The formation of gapped and hemireplicated molecules is partly dependent on the action of the Exo1 nuclease (Cotta-Ramusino et al., 2005). Ablation of Exo1 also reduces the accumulation of reversed forks (Cotta-Ramusino et al., 2005), suggesting that Exol might either promote their resolution by resecting reversed strands or the formation of extended ssDNA gaps precluding nascent strand re-annealing. Exol induces fork instability and lethality in checkpoint deficient cells that replicate damaged templates (Segurado and Diffley, 2008). Exo1 is phosphorylated by Rad53 (Smolka et al., 2007) and it has been suggested that targeting by Rad53 might downregulate Exol activity (Morin et al., 2008). This is in agreement with the notion that the checkpoint suppresses Exol-mediated processing of normal and/or aberrant DNA structures at stalled replication forks, thus preventing fork breakdown (Segurado and Diffley, 2008). Exo1-dependent processing of collapsed forks is likely to prime unscheduled recombination events giving rise to gross chromosomal re-arrangements in checkpoint deficient cells (Myung and Kolodner, 2002; Kaochar et al., 2010). It has been proposed that further nucleolytic cleavage could target collapsed forks contributing to the formation of DNA breaks or as part of DNA repair attempts (Branzei and Foiani, 2009). The identity of the factors mediating such processing and the implication of the checkpoint in suppressing their action remain to be discovered.

Several replisome components including DNA polymerase $\alpha$ and $\delta$ subunits, as well as components of the Mcm2-7 and GINS helicase complexes are direct targets of Mecl and Rad53 phosphorylation (Smolka et al., 2007; Chen et al., 2010; Randell et al., 2010) (Table 2) and the association of replicative polymerases and the Mcm2-7 helicase complex to stalled replication forks is impaired in checkpoint kinases mutants (Cobb et al., 2003, 2005; Lucca et al., 2004). These observations led to the suggestion that checkpoint kinases regulate the tethering of essential replisome components to fork DNA and that the loss of this tethering is the reason for checkpoint mutants inability to resume DNA synthesis. In agreement with this hypothesis, some replisome factors, such as the Mcm2-7 complex, cannot be re-loaded to replication forks (Labib et al., 2000), nor do efficient mechanisms for re-loading essential replication factors to collapsed forks seem to operate (Zegerman and Diffley, 2009). A recent study showed that the association between replisome components isolated by immunoprecipitation following genotoxic treatment is equivalent in wild type cells and checkpoint mutants (De Piccoli et al., 2012), suggesting that replisomes do not suffer gross structural alterations as a result of fork collapse. The same study showed that DNA polymerase $\alpha$ and Mcm2-7 complex components remained associated to a large fraction of replication forks following $\mathrm{HU}$ treatment in the absence of checkpoint kinases, raising the possibility that lack of phosphorylation of replisome components, rather than dissociation from replication forks, accounts for the inability of cells to re-start DNA synthesis (De Piccoli et al., 2012). Interestingly, forks from which replisome components are lost correlate with those emanated from earliest origins, though the specific determinants of the susceptibility of these forks to replisome dissociation are unclear.

The relative contribution of replisome destabilization, replication fork reversal, and the nucleolytic processing of replication intermediates to the loss of replication fork functionality is unclear. It is likely that the three processes interplay to promote fork collapse if not effectively suppressed by checkpoint kinases (Figure 4). It is tantalizing to speculate that checkpoint kinases might somehow contribute to maintain the association of DNA polymerases with nascent DNA chains, perhaps by restraining helicase activity, or DNA polymerases processivity through direct phosphorylation events. DNA polymerases might be physically displaced from the $3^{\prime}$ termini of nascent strands by an excessive tracking of the replisome along the parental DNA, thus losing their capacity to continue DNA synthesis. The mechanical stress imposed by positive supercoiling may also contribute to displacing DNA polymerases from $3^{\prime}$ termini by peeling-off the nascent strands from the parental template. Nucleolytic processing at forks might in turn be favored by the exposure of the termini of nascent strands upon replisome dislodgement or fork reversal (Figure 4). Nucleolytic cleavage of ssDNA or branched structures could eventually generate discontinuities allowing the dissociation of replisome factors topologically linked to DNA (such as the Mcm2-7 complex or PCNA rings), thus accounting for the replisome loss observed in checkpoint mutants at early established replication forks (Cobb et al., 2003, 2005; Lucca et al., 2004; De Piccoli et al., 2012). Further work will be required to understand the checkpoint-mediated mechanisms protecting replication forks and their relative impact on genome integrity maintenance in response to different replication stress-inducing agents in detail.

\section{CHECKPOINT SIGNALING REVERSION AND RESTORATION OF NORMAL CELLULAR PHYSIOLOGY}

As discussed above, checkpoint activation in response to replication stress has a profound impact on several cellular processes, including modulation of the transcriptional program, replicon dynamics, and cell cycle progression. Checkpoint kinases phosphorylate and/or regulate the expression levels of a large number of factors. Once replication stress is overcome, normal cellular physiology needs to be restored. This requires shutting-off the checkpoint signaling cascade, as well as the reversion of posttranslational modifications and expression level changes of checkpoint transducers and effectors. 


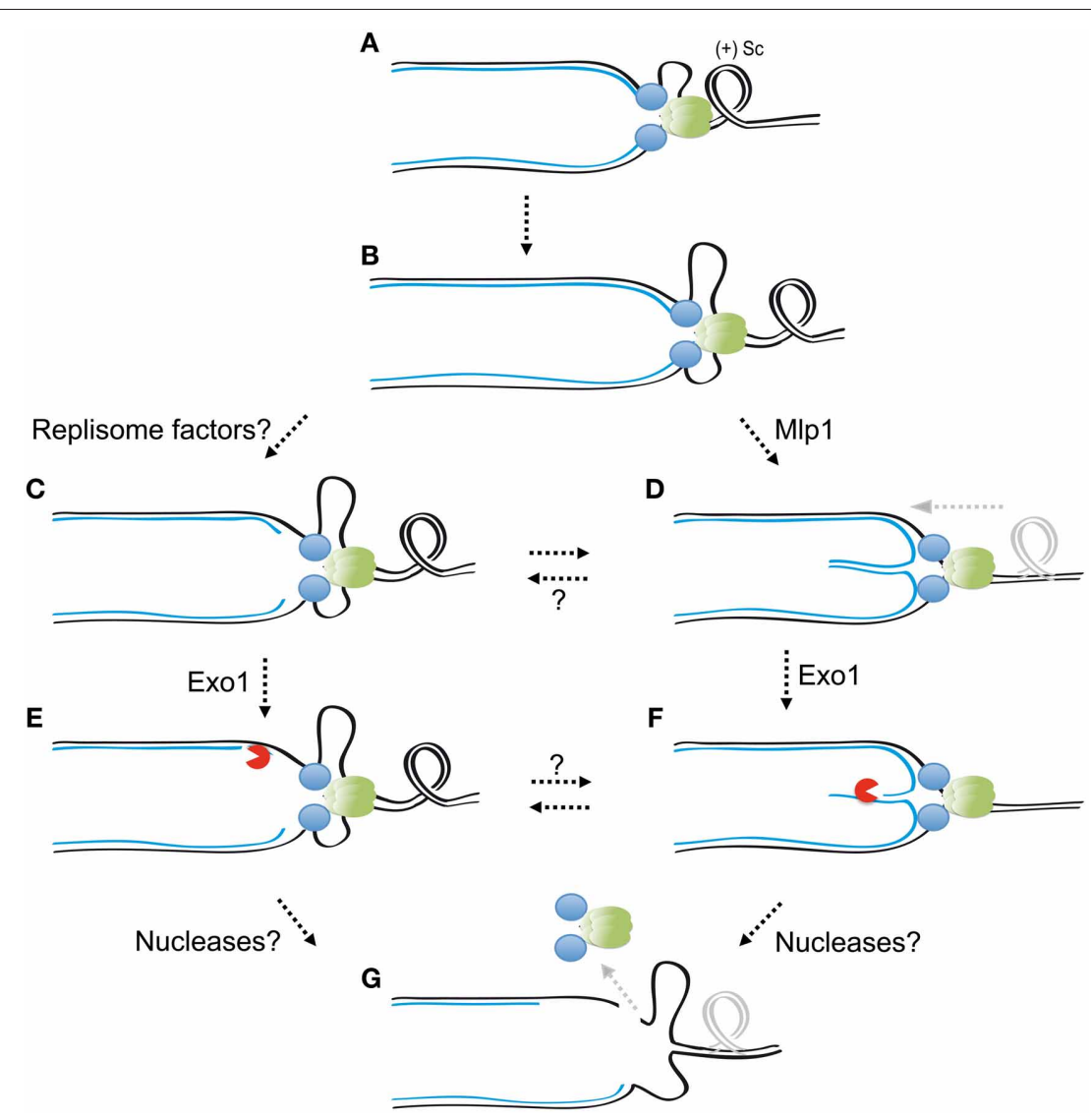

FIGURE 4 | Interplay between checkpoint-mediated mechanisms counteracting replication fork collapse. In unperturbed conditions replication fork advancement generates positive supercoiling (A). Fork stalling and helicase/polymerases uncoupling generate extended ssDNA tracks triggering checkpoint activation (B). Replisome factors targeting by checkpoint kinases might limit replisome tracking and thus prevent the dissociation of DNA polymerases from nascent strands termini (C). Checkpoint kinases also inhibit Mlp1 function, allowing positive supercoiling diffusion, and counteracting replication fork reversal (D). In the absence of checkpoint kinases Exo1 could access exposed nascent strands termini and generate extended ssDNA tracks $(\mathbf{E}, \mathbf{F})$. Further nucleolytic processing of SSDNA tracks or branch cleavage activities could determine the formation of DNA breaks, which may in turn favor replisome dissociation from fork DNA (G). The combined action of these checkpoint-suppressed events likely contributes to the loss of functional integrity of stalled forks. Factors phosphorylated and potentially inhibited by checkpoint kinases to suppress abnormal fork transitions are indicated. Replisome components are represented as green and blue circles.
A first mechanism contributing to checkpoint signaling inactivation is likely to be the elimination of upstream signals recognized by checkpoint sensors at replication forks. Upon resumption of DNA synthesis, ssDNA tracks shorten as DNA polymerases catch up with each other or with helicases, thus limiting further Ddc2-mediated recruitment and activation of $\mathrm{Mec1}$. Interruption of Mec1 signaling may be sufficient to shutoff the checkpoint response, as Mecl activity downregulation by overexpression of a dominant negative MEC1 allele results in premature Rad53 dephosphorylation (Paciotti et al., 2001). However, an exclusively passive mechanism is unlikely to account for the rapid checkpoint inactivation observed after the removal of replication stress-inducing drugs (Travesa et al., 2008), indicating that mechanisms exist that actively revert checkpoint signaling.

A straightforward way to actively interrupt checkpoint signaling is to reverse the phosphorylation events mediated by checkpoint kinases. Work over the last years has focused on the inactivation of Rad53 kinase through dephosphorylation, which is quickly achieved upon the removal of replication stress inducing agents. Rad53 dephosphorylation tightly correlates with the downregulation of its kinase activity and does not require protein synthesis (Pellicioli et al., 1999). Budding yeast phosphatases Ptc2, Ptc3, and Pph3/Psy2 are required for Rad53 dephosphorylation following replication stress (O’Neill et al., 2007; Szyjka et al., 2008). The Pph3 phosphatase and its regulatory subunit Psy2 form a complex that dephosphorylates Rad53 in vitro and it has been suggested that they directly inactivate Rad53 (O'Neill et al., 2007). It is unclear, however, whether Pph3 has other important targets in checkpoint inactivation (Keogh et al., 2006). Ptc2 and $\mathrm{Ptc} 3$ are type $2 \mathrm{C}$ protein phosphatases with redundant functions in the checkpoint response (Leroy et al., 2003). Ptc2 and Ptc3 can bind Rad53 and directly mediate its dephosphorylation (Leroy et al., 2003; Guillemain et al., 2007). Both ptc2, ptc3, and pph3/psy2 deletion mutants accumulate hyperphosphorylated Rad53 upon treatment with HU or MMS (Travesa et al., 2008). Ptc2/Ptc3 human homologs Wip1/PPM1D also play important 
roles in the reversal of DNA damage checkpoint responses by dephosphorylating and inactivating checkpoint components (for review see Heideker et al., 2007; Clemenson and MarsolierKergoat, 2009).

Interestingly, checkpoint inactivation has different genetic requirements upon continuous exposure to (adaptation) or during the recovery from replication stress. Pph3/Psy2 complex mediates Rad53 dephosphorylation both during adaptation and recovery from $\mathrm{HU}$ or MMS treatments, while Ptc2 and Ptc3 are dispensable during recovery (Travesa et al., 2008). The Glc7/protein phosphatase 1, recently shown to be involved in checkpoint inactivation, acts both during adaptation and recovery following HU treatment, but is dispensable during MMS exposure (Bazzi et al., 2010). These differential genetic requirements for checkpoint inactivation point to the existence of distinct modifications of checkpoint factors that might be crucial for checkpoint function in different cellular contexts or upon different replication stress-inducing stimuli. Recent observations indicate that checkpoint inactivation can also be achieved through degradation or cellular sorting of checkpoint transducers and/or effectors. Mammalian CHK1 effector kinase is inactivated through proteasome-dependent downregulation upon ATR-mediated phosphorylation, which leads to both CHK1 activation and its marking for degradation (Zhang et al., 2005). Furthermore, the Mrcl human homolog CLASPIN is targeted for degradation in response to HU treatment, thereby promoting CHK1 inactivation (Mailand et al., 2006; Mamely et al., 2006; Peschiaroli et al., 2006).

Reversion of checkpoint-induced changes in the transcriptional program is promoted by the establishment of negative feedback loops (Smolka et al., 2012). As mentioned above, Crt1 and Nrm1 are phosphorylated by checkpoint kinases, which remove them from damage inducible and MBF targets gene promoters (Huang et al., 1998; Travesa et al., 2012). CRT1 and NRM1 promoters are bound by Crt1 and Nrm1, respectively, and therefore their transcription is upregulated along with that of other damage inducible genes upon checkpoint activation. Overexpression of Crt1 and Nrm1 provides a simple mechanism to limit checkpoint-mediated transcriptional changes, as accumulating Crt1 and Nrm1 might escape regulation by checkpoint kinases to mediate the repression of the relevant genes. This mechanism might be particularly efficient upon concomitant inactivation of checkpoint signal transduction, as newly synthesized Crt1 and Nrm1 would not be inhibited by checkpoint kinases.

Untimely persistence of checkpoint signaling might impact on replication dynamics. It has been suggested that checkpoint kinases slow down replication fork progression rates by directly phosphorylating replisome components (Labib and De Piccoli, 2011). Consistently, DNA synthesis resumption at MMS stalled forks is severely impaired in cells lacking Pph3 phosphatase (Szyjka et al., 2008). Such slowly progressing forks would need to traverse longer genomic regions before fusing, as persistent checkpoint signaling may also suppress late origin firing. Furthermore, the fidelity of DNA synthesis at these slow-progressing forks might be additionally compromised by the persistence of abnormally elevated dNTP pools. Therefore, a failure to promptly inactivate the checkpoint response once cells overcome replication stress might greatly impact genome integrity. In the future, it will be interesting to analyze which cellular mechanisms revert checkpoint signaling following different kinds of replication stress induced by diverse chemotherapeutic agents, as well as to study the impact of checkpoint inactivation defects on malignant transformation and cancer development.

\section{CHECKPOINT EVOLUTION AS AN ANTICANCER BARRIER IN MULTICELLULAR ORGANISMS}

Apical checkpoint kinases share homology with the PI3-related TOR kinases, which modulate cellular metabolism in response to nutrient availability (Lovejoy and Cortez, 2009). As mentioned above, budding yeast checkpoint kinases play an essential role in regulating dNTP pools even in the absence of replication stress (Zhao et al., 1998). It is therefore reasonable to think that the ancestral role of checkpoint kinases might have been to modulate the cellular metabolism in order to readily meet the elevated demand for dNTPs imposed by DNA replication during S phase. This function may have become crucial to ensure DNA replication fidelity in unicellular eukaryotes in which growth and proliferation greatly depend on nutrient availability (Alberghina et al., 2012). In this view, checkpoint kinases might have become progressively specialized in sensing and responding to stimuli requiring the upregulation of $\mathrm{dNTP}$ levels such as replication stalling by exogenous toxins or the repair of DNA damage. The evolutionary advantage of being able to survive such genotoxic insults might have favored checkpoint kinases gaining control over other cellular processes essential for replication integrity such as the control of cell cycle progression, replication origin firing, or replication fork stabilization. Checkpoint control of these functions is conserved in multicellular organisms (Jackson and Bartek, 2009; Ciccia and Elledge, 2010), although in higher eukaryotes the checkpoint response regulates mechanisms driving cells out of proliferating pools such as senescence or apoptosis. This might relate to the fact that cell proliferation decisions in higher eukaryotes are integrated at the organism level and are relatively independent from environmental nutrient availability.

In recent years it has emerged that the checkpoint response behaves as a barrier preventing tumorigenesis at early stages of cancer development (Bartek et al., 2007a; Halazonetis et al., 2008). This idea is supported by the observations that tumor cells, unlike other highly proliferating cells, show constitutively activated checkpoint kinases and markers of DNA breakage (Bartkova et al., 2005; Gorgoulis et al., 2005) and that oncogene activation induces replication stress, fork collapse, and formation of DNA breaks (Bartkova et al., 2006; Di Micco et al., 2006). Replication stress and DNA damage in this context may emerge from massive interference of replication forks with unscheduled oncogene-induced transcription (Bermejo et al., 2012b). In early pre-invasive lesions the checkpoint response is thought to promote pre-malignant cells removal from proliferating pools into senescence or apoptosis (Bartek et al., 2007b). Mutations or epigenetic silencing of checkpoint genes might result in an increased accumulation of DNA breaks owing to faulty fork stabilization, as well as to the loss of the checkpoint-mediated restraints to proliferation. Hence, cancer cells could proliferate and expand at 
the expense of an increased genomic instability, thus accelerating tumorigenesis.

Future research should focus on integrating the current insight on checkpoint-mediated replication fork protection with a deeper knowledge on the determinants driving fork collapse in cells experiencing oncogene-induced replication stress. It will also be interesting to explore the connections between checkpoint inactivation mechanisms, replication dynamics, and genome integrity maintenance; and how checkpoint signaling modulation might interplay with the checkpoint function in suppressing cell proliferation to act as an anticancer barrier.

\section{REFERENCES}

Admire, A., Shanks, L., Danzl, N., Wang, M., Weier, U., Stevens, W., et al. (2006). Cycles of chromosome instability are associated with a fragile site and are increased by defects in DNA replication and checkpoint controls in yeast. Genes Dev. 20, 159-173.

Alberghina, L., Mavelli, G., Drovandi, G., Palumbo, P., Pessina, S., Tripodi, F., et al. (2012). Cell growth and cell cycle in Saccharomyces cerevisiae: basic regulatory design and protein-protein interaction network. Biotechnol. Adv. 30, 52-72.

Alcasabas, A. A., Osborn, A. J., Bachant, J., Hu, F., Werler, P. J., Bousset, K., et al. (2001). Mrcl transduces signals of DNA replication stress to activate Rad53. Nat. Cell Biol. 3, 958-965.

al-Khodairy, F., and Carr, A. M. (1992). DNA repair mutants defining G2 checkpoint pathways in Schizosaccharomyces pombe. EMBO J. 11, 1343-1350.

Alzu, A., Bermejo, R., Begnis, M., Lucca, C., Piccini, D., Carotenuto, W., et al. (2012). Senataxin associates with replication forks to protect fork integrity across RNApolymerase-II-transcribed genes. Cell 151, 835-846.

Andreson, B. L., Gupta, A., Georgieva, B. P., and Rothstein, R. (2010). The ribonucleotide reductase inhibitor, Smll, is sequentially phosphorylated, ubiquitylated and degraded in response to DNA damage. Nucleic Acids Res. 38, 6490-6501.

Azvolinsky, A., Dunaway, S., Torres, J. Z., Bessler, J. B., and Zakian, V. A. (2006). The, S. cerevisiae Rrm3p DNA helicase moves with the replication fork and affects replication of all yeast chromosomes. Genes Dev. 20,3104-3116.

Azvolinsky, A., Giresi, P. G., Lieb, J. D., and Zakian, V. A. (2009). Highly transcribed RNA polymerase II genes are impediments to replication fork progression in
Saccharomyces cerevisiae. Mol. Cell 34, 722-734.

Bartek, J., Bartkova, J., and Lukas, J. (2007a). DNA damage signalling guards against activated oncogenes and tumour progression. Oncogene 26, 7773-7779.

Bartek, J., Lukas, J., and Bartkova, J. (2007b). DNA damage response as an anti-cancer barrier: damage threshold and the concept of 'conditional haploinsufficiency'. Cell Cycle 6, 2344-2347.

Bartkova, J., Horejsi, Z., Koed, K., Kramer, A., Tort, F., Zieger, K., et al. (2005). DNA damage response as a candidate anti-cancer barrier in early human tumorigenesis. Nature $434,864-870$.

Bartkova, J., Rezaei, N., Liontos, M., Karakaidos, P., Kletsas, D., Issaeva, N., et al. (2006). Oncogene-induced senescence is part of the tumorigenesis barrier imposed by DNA damage checkpoints. Nature 444, 633-637.

Bashkirov, V. I., Bashkirova, E. V., Haghnazari, E., and Heyer, W. D. (2003). Direct kinase-to-kinase signaling mediated by the FHA phosphoprotein recognition domain of the Dun1 DNA damage checkpoint kinase. Mol. Cell. Biol. 23, 1441-1452.

Bazzi, M., Mantiero, D., Trovesi, C., Lucchini, G., and Longhese, M. P. (2010). Dephosphorylation of gamma $\mathrm{H} 2 \mathrm{~A}$ by Glc7/protein phosphatase 1 promotes recovery from inhibition of DNA replication. Mol. Cell. Biol. 30, 131-145.

Bell, S. P., and Dutta, A. (2002). DNA replication in eukaryotic cells. Annu. Rev. Biochem. 71, 333-374.

Bentley, N. J., Holtzman, D. A., Flaggs, G., Keegan, K. S., Demaggio, A., Ford, J. C., et al. (1996). The Schizosaccharomyces pombe $\operatorname{rad} 3$ checkpoint gene. $E M B O$ J. 15, 6641-6651.

Berens, T. J., and Toczyski, D. P. (2012). Colocalization of Mec1 and $\mathrm{Mrcl}$ is sufficient for Rad53

\section{ACKNOWLEDGMENTS}

We apologize for all the relevant findings and studies that could not be discussed in this review due to space limitations. We thank Miguel García-Díaz, Monica Segurado, Avelino Bueno, and all members of our laboratory for discussions and critical reading of the manuscript, and Lucy Jane Bock for style supervision. Rodrigo Bermejo laboratory was supported by the Spanish Ministry of Science and Innovation (RYC-2010-07131 and BFU2011-24909) and the European Community's FP7 (under grant agreement ${ }^{\circ}$ 293770). The IBFG acknowledges support from "Ramón Areces Foundation."

phosphorylation in vivo. Mol. Biol. Cell 23, 1058-1067.

Bermejo, R., Capra, T., GonzalezHuici, V., Fachinetti, D., Cocito, A. Natoli, G., et al. (2009). Genomeorganizing factors Top2 and Hmol prevent chromosome fragility at sites of $\mathrm{S}$ phase transcription. Cell $138,870-884$.

Bermejo, R., Capra, T., Jossen, R., Colosio, A., Frattini, C., Carotenuto, W., et al. (2011). The replication checkpoint protects fork stability by releasing transcribed genes from nuclear pores. Cell 146, 233-246.

Bermejo, R., Doksani, Y., Capra, T., Katou, Y. M., Tanaka, H., Shirahige, K., et al. (2007). Top1- and Top2mediated topological transitions at replication forks ensure fork progression and stability and prevent DNA damage checkpoint activation. Genes Dev. 21, 1921-1936.

Bermejo, R., Kumar, A., and Foiani, M. (2012a). Preserving the genome by regulating chromatin association with the nuclear envelope. Trends Cell Biol. 22, 465-473.

Bermejo, R., Lai, M. S., and Foiani, M. (2012b). Preventing replication stress to maintain genome stability: resolving conflicts between replication and transcription. Mol. Cell 45, 710-718.

Bester, A. C., Roniger, M., Oren, Y. S., Im, M. M., Sarni, D., Chaoat, M., et al. (2011). Nucleotide deficiency promotes genomic instability in early stages of cancer development. Cell 145, 435-446.

Boddy, M. N., and Russell, P. (2001). DNA replication checkpoint. Curr. Biol. 11, R953-R956.

Branzei, D., and Foiani, M. (2009). The checkpoint response to replication stress. DNA Repair (Amst.) 8, 1038-1046.

Branzei, D., and Foiani, M. (2010). Maintaining genome stability at the replication fork. Nat. Rev. Mol. Cell Biol. 11, 208-219.

Byun, T. S., Pacek, M., Yee, M. C., Walter, J. C., and Cimprich, K.
A. (2005). Functional uncoupling of MCM helicase and DNA polymerase activities activates the ATRdependent checkpoint. Genes Dev. 19, 1040-1052.

Carter, C. D., Kitchen, L. E., Au, W. C., Babic, C. M., and Basrai, M. A. (2005). Loss of SOD1 and LYS7 sensitizes Saccharomyces cerevisiae to hydroxyurea and DNA damage agents and downregulates MEC pathway effectors. Mol. Cell. Biol. 25, 10273-10285.

Cha, R. S., and Kleckner, N. (2002). ATR homolog Mecl promotes fork progression, thus averting breaks in replication slow zones. Science 297, 602-606.

Chabes, A., Domkin, V., and Thelander, L. (1999). Yeast Smll, a protein inhibitor of ribonucleotide reductase. J. Biol. Chem. 274, 36679-36683.

Chabes, A., Georgieva, B., Domkin, V., Zhao, X., Rothstein, R., and Thelander, L. (2003). Survival of DNA damage in yeast directly depends on increased dNTP levels allowed by relaxed feedback inhibition of ribonucleotide reductase. Cell 112, 391-401.

Chen, S. H., Albuquerque, C. P., Liang, J., Suhandynata, R. T., and Zhou, H. (2010). A proteome-wide analysis of kinase-substrate network in the DNA damage response. J. Biol. Chem. 285, 12803-12812.

Chen, S. H., and Zhou, H. (2009). Reconstitution of Rad53 activation by $\mathrm{Mecl}$ through adaptor protein Mrc1. J. Biol. Chem. 284, 18593-18604.

Ciccia, A., and Elledge, S. J. (2010). The DNA damage response: making it safe to play with knives. Mol. Cell 40, 179-204.

Clemenson, C., and Marsolier-Kergoat, M. C. (2009). DNA damage checkpoint inactivation: adaptation and recovery. DNA Repair (Amst.) 8, 1101-1109.

Cobb, J. A., Bjergbaek, L., Shimada, K., Frei, C., and Gasser, S. M. (2003). 
DNA polymerase stabilization at stalled replication forks requires Mec1 and the RecQ helicase Sgs1. EMBO J. 22, 4325-4336.

Cobb, J. A., Schleker, T., Rojas, V., Bjergbaek, L., Tercero, J. A., and Gasser, S. M. (2005). Replisome instability, fork collapse, and gross chromosomal rearrangements arise synergistically from Mecl kinase and RecQ helicase mutations. Genes Dev. 19, 3055-3069.

Cotta-Ramusino, C., Fachinetti, D., Lucca, C., Doksani, Y., Lopes, M., Sogo, J., et al. (2005). Exo1 processes stalled replication forks and counteracts fork reversal in checkpoint-defective cells. Mol. Cell 17, 153-159.

de Bruin, R. A., Kalashnikova, T. I., Aslanian, A., Wohlschlegel, J., Chahwan, C., Yates, J. R. 3rd., et al. (2008). DNA replication checkpoint promotes G1-S transcription by inactivating the MBF repressor Nrm1. Proc. Natl. Acad. Sci. U.S.A. 105, 11230-11235.

de Bruin, R. A., Kalashnikova, T. I., Chahwan, C., McDonald, W. H., Wohlschlegel, J., Yates, J. 3rd., et al. (2006). Constraining G1specific transcription to late G1 phase: the MBF-associated corepressor Nrm1 acts via negative feedback. Mol. Cell 23, 483-496.

De Piccoli, G., Katou, Y., Itoh, T., Nakato, R., Shirahige, K., and Labib, K. (2012). Replisome stability at defective DNA replication forks is independent of S phase checkpoint kinases. Mol. Cell 45, 696-704.

Desany, B. A., Alcasabas, A. A., Bachant, J. B., and Elledge, S. J. (1998). Recovery from DNA replicational stress is the essential function of the S-phase checkpoint pathway. Genes Dev. 12, 2956-2970.

Deshpande, A. M., and Newlon, C. S. (1996). DNA replication fork pause sites dependent on transcription. Science 272, 1030-1033.

Di Micco, R., Fumagalli, M., Cicalese, A., Piccinin, S., Gasparini, P., Luise, C., et al. (2006). Oncogeneinduced senescence is a DNA damage response triggered by DNA hyper-replication. Nature 444, 638-642.

Dion, V., Kalck, V., Horigome, C., Towbin, B. D., and Gasser, S. M. (2012). Increased mobility of double-strand breaks requires Mec1, Rad9 and the homologous recombination machinery. Nat. Cell Biol. 14, 502-509.

Doksani, Y., Bermejo, R., Fiorani, S., Haber, J. E., and Foiani, M. (2009). Replicon dynamics, dormant origin firing, and terminal fork integrity after double-strand break formation. Cell 137, 247-258.

Domkin, V., Thelander, L., and Chabes, A. (2002). Yeast DNA damage-inducible Rnr3 has a very low catalytic activity strongly stimulated after the formation of a cross-talking Rnr1/Rnr3 complex. J. Biol. Chem. 277, 18574-18578.

Enoch, T., Carr, A. M., and Nurse, P. (1992). Fission yeast genes involved in coupling mitosis to completion of DNA replication. Genes Dev. 6, 2035-2046.

Enoch, T., and Nurse, P. (1990). Mutation of fission yeast cell cycle control genes abolishes dependence of mitosis on DNA replication. Cell 60, 665-673.

Enserink, J. M., Smolka, M. B., Zhou, H., and Kolodner, R. D. (2006). Checkpoint proteins control morphogenetic events during DNA replication stress in Saccharomyces cerevisiae. J. Cell Biol. 175, 729-741.

Feng, W., Collingwood, D., Boeck, M. E., Fox, L. A., Alvino, G. M., Fangman, W. L., et al. (2006). Genomic mapping of single-stranded DNA in hydroxyurea-challenged yeasts identifies origins of replication. Nat. Cell Biol. 8, 148-155.

Feng, W., Di Rienzi, S. C., Raghuraman, M. K., and Brewer, B. J. (2011). Replication stress-induced chromosome breakage is correlated with replication fork progression and is preceded by single-stranded DNA formation. G3 (Bethesda) 1, 327-335.

Gambus, A., Jones, R. C., SanchezDiaz, A., Kanemaki, M., Van Deursen, F., Edmondson, R. D., et al. (2006). GINS maintains association of Cdc45 with MCM in replisome progression complexes at eukaryotic DNA replication forks. Nat. Cell Biol. 8, 358-366.

Ghavidel, A., Kislinger, T., Pogoutse, O., Sopko, R., Jurisica, I., and Emili, A. (2007). Impaired tRNA nuclear export links DNA damage and cellcycle checkpoint. Cell 131, 915-926.

Gomez-Gonzalez, B., Garcia-Rubio, M., Bermejo, R., Gaillard, H., Shirahige, K., Marin, A., et al. (2011). Genome-wide function of THO/TREX in active genes prevents R-loop-dependent replication obstacles. EMBO J. 30, 3106-3119.

Gorgoulis, V. G., Vassiliou, L. V., Karakaidos, P., Zacharatos, P., Kotsinas, A., Liloglou, T., et al. (2005). Activation of the DNA damage checkpoint and genomic instability in human precancerous lesions. Nature 434, 907-913.
Greenwell, P. W., Kronmal, S. L., Porter, S. E., Gassenhuber, J., Obermaier, B., and Petes, T. D. (1995). TEL1, a gene involved in controlling telomere length in S. cerevisiae, is homologous to the human ataxia telangiectasia gene. Cell 82, 823-829.

Guillemain, G., Ma, E., Mauger, S. Miron, S., Thai, R., Guerois, R., et al. (2007). Mechanisms of checkpoint kinase Rad53 inactivation after a double-strand break in Saccharomyces cerevisiae. Mol. Cell Biol. 27, 3378-3389.

Halazonetis, T. D., Gorgoulis, V. G., and Bartek, J. (2008). An oncogeneinduced DNA damage model for cancer development. Science 319, 1352-1355.

Heideker, J., Lis, E. T., and Romesberg, F. E. (2007). Phosphatases, DNA damage checkpoints and checkpoint deactivation. Cell Cycle 6, 3058-3064.

Huang, M., Zhou, Z., and Elledge, S. J. (1998). The DNA replication and damage checkpoint pathways induce transcription by inhibition of the Crt1 repressor. Cell 94 595-605.

Iftode, C., Daniely, Y., and Borowiec, J. A. (1999). Replication protein A (RPA): the eukaryotic SSB. Crit. Rev. Biochem. Mol. Biol. 34, 141-180.

Jackson, S. P., and Bartek, J. (2009). The DNA-damage response in human biology and disease. Nature 461, 1071-1078.

Johnson, A., and O'Donnell, M. (2005). Cellular DNA replicases: components and dynamics at the replication fork. Annu. Rev. Biochem. 74, 283-315.

Kaochar, S., Shanks, L., and Weinert, T. (2010). Checkpoint genes and Exo1 regulate nearby inverted repeat fusions that form dicentric chromosomes in Saccharomyces cerevisiae. Proc. Natl. Acad. Sci. U.S.A. 107, 21605-21610.

Kastan, M. B., and Bartek, J. (2004) Cell-cycle checkpoints and cancer. Nature 432, 316-323.

Katou, Y., Kanoh, Y., Bando, M., Noguchi, H., Tanaka, H., Ashikari, T., et al. (2003). S-phase checkpoint proteins Tofl and $\mathrm{Mrcl}$ form a stable replication-pausing complex. Nature 424, 1078-1083.

Kawabata, T., Luebben, S. W. Yamaguchi, S., Ilves, I., Matise, I., Buske, T., et al. (2011). Stalled fork rescue via dormant replication origins in unchallenged $\mathrm{S}$ phase promotes proper chromosome segregation and tumor suppression. Mol. Cell 41, 543-553.

Keogh, M. C., Kim, J. A., Downey, M., Fillingham, J., Chowdhury, D.,
Harrison, J. C., et al. (2006). A phosphatase complex that dephosphorylates gammaH2AX regulates DNA damage checkpoint recovery. Nature 439, 497-501.

Koch, C., Moll, T., Neuberg, M., Ahorn, H., and Nasmyth, K. (1993). A role for the transcription factors Mbp1 and Swi4 in progression from G1 to S phase. Science 261, 1551-1557.

Kohler, A., and Hurt, E. (2007). Exporting RNA from the nucleus to the cytoplasm. Nat. Rev. Mol. Cell Biol. 8, 761-773.

Koster, D. A., Crut, A., Shuman, S., Bjornsti, M. A., and Dekker, N. H. (2010). Cellular strategies for regulating DNA supercoiling: a single-molecule perspective. Cell 142, 519-530.

Krishnan, V., Nirantar, S., Crasta, K., Cheng, A. Y., and Surana, U. (2004). DNA replication checkpoint prevents precocious chromosome segregation by regulating spindle behavior. Mol. Cell 16, 687-700.

Labib, K., and De Piccoli, G. (2011). Surviving chromosome replication: the many roles of the S-phase checkpoint pathway. Philos. Trans. R. Soc. Lond. B Biol. Sci. 366, 3554-3561.

Labib, K., and Hodgson, B. (2007). Replication fork barriers: pausing for a break or stalling for time? EMBO Rep. 8, 346-353.

Labib, K., Tercero, J. A., and Diffley, J. F. (2000). Uninterrupted MCM2-7 function required for DNA replication fork progression. Science 288, 1643-1647.

Lee, Y. D., and Elledge, S. J. (2006). Control of ribonucleotide reductase localization through an anchoring mechanism involving Wtm1. Genes Dev. 20, 334-344.

Lee, Y. D., Wang, J., Stubbe, J., and Elledge, S. J. (2008). Difl is a DNAdamage-regulated facilitator of nuclear import for ribonucleotide reductase. Mol. Cell 32, 70-80.

Lengronne, A., McIntyre, J., Katou, Y., Kanoh, Y., Hopfner, K. P., Shirahige, K., et al. (2006). Establishment of sister chromatid cohesion at the $S$. cerevisiae replication fork. Mol. Cell 23, 787-799.

Leroy, C., Lee, S. E., Vaze, M. B., Ochsenbein, F., Guerois, R., Haber, J. E., et al. (2003). PP2C phosphatases Ptc2 and Ptc3 are required for DNA checkpoint inactivation after a double-strand break. Mol. Cell 11, 827-835.

Li, B., and Reese, J. C. (2001). Ssn6Tup1 regulates RNR3 by positioning nucleosomes and affecting the chromatin structure at the upstream repression sequence. J. Biol. Chem. 276, 33788-33797. 
Longhese, M. P., Clerici, M., and Lucchini, G. (2003). The S-phase checkpoint and its regulation in Saccharomyces cerevisiae. Mutat. Res. 532, 41-58.

Longhese, M. P., Mantiero, D., and Clerici, M. (2006). The cellular response to chromosome breakage. Mol. Microbiol. 60, 1099-1108.

Lopes, M., Cotta-Ramusino, C., Pellicioli, A., Liberi, G., Plevani, P., Muzi-Falconi, M., et al. (2001). The DNA replication checkpoint response stabilizes stalled replication forks. Nature 412, 557-561.

Lopez-Mosqueda, J., Maas, N. L., Jonsson, Z. O., Defazio-Eli, L. G., Wohlschlegel, J., and Toczyski, D. P. (2010). Damage-induced phosphorylation of Sld3 is important to block late origin firing. Nature 467, 479-483.

Lou, H., Komata, M., Katou, Y., Guan, Z., Reis, C. C., Budd, M., et al. (2008). Mrc1 and DNA polymerase epsilon function together in linking DNA replication and the $S$ phase checkpoint. Mol. Cell 32, 106-117.

Lovejoy, C. A., and Cortez, D. (2009). Common mechanisms of PIKK regulation. DNA Repair (Amst.) 8, 1004-1008.

Lucca, C., Vanoli, F., Cotta-Ramusino, C., Pellicioli, A., Liberi, G., Haber, J., et al. (2004). Checkpoint-mediated control of replisome-fork association and signalling in response to replication pausing. Oncogene 23, 1206-1213.

Lupardus, P. J., Byun, T., Yee, M. C., Hekmat-Nejad, M., and Cimprich, K. A. (2002). A requirement for replication in activation of the ATRdependent DNA damage checkpoint. Genes Dev. 16, 2327-2332.

Mailand, N., Bekker-Jensen, S., Bartek, J., and Lukas, J. (2006). Destruction of Claspin by SCFbetaTrCP restrains Chk1 activation and facilitates recovery from genotoxic stress. $\mathrm{Mol}$. Cell 23, 307-318.

Mallory, J. C., and Petes, T. D. (2000). Protein kinase activity of Tellp and Meclp, two Saccharomyces cerevisiae proteins related to the human ATM protein kinase. Proc. Natl. Acad. Sci. U.S.A. 97, 13749-13754.

Mamely, I., Van Vugt, M. A., Smits, V. A., Semple, J. I., Lemmens, B., Perrakis, A., et al. (2006). Pololike kinase- 1 controls proteasomedependent degradation of Claspin during checkpoint recovery. Curr. Biol. 16, 1950-1955.

Mine-Hattab, J., and Rothstein, R. (2012). Increased chromosome mobility facilitates homology search during recombination. Nat. Cell Biol. 14, 510-517.

Moldovan, G. L., Pfander, B., and Jentsch, S. (2007). PCNA, the maestro of the replication fork. Cell 129, 665-679.

Morin, I., Ngo, H. P., Greenall, A., Zubko, M. K., Morrice, N., and Lydall, D. (2008). Checkpointdependent phosphorylation of Exol modulates the DNA damage response. EMBO J. 27, 2400-2410.

Morrow, D. M., Tagle, D. A., Shiloh, Y., Collins, F. S., and Hieter, P. (1995). TEL1, an S. cerevisiae homolog of the human gene mutated in ataxia telangiectasia, is functionally related to the yeast checkpoint gene MEC1. Cell 82, 831-840.

Myung, K., Datta, A., and Kolodner, R. D. (2001). Suppression of spontaneous chromosomal rearrangements by $\mathrm{S}$ phase checkpoint functions in Saccharomyces cerevisiae. Cell 104, 397-408.

Myung, K., and Kolodner, R. D. (2002). Suppression of genome instability by redundant S-phase checkpoint pathways in Saccharomyces cerevisiae. Proc. Natl. Acad. Sci. U.S.A. 99, 4500-4507.

Nedelcheva-Veleva, M. N., Krastev, D. B., and Stoynov, S. S. (2006). Coordination of DNA synthesis and replicative unwinding by the $S$ phase checkpoint pathways. Nucleic Acids Res. 34, 4138-4146.

Nguyen, V. C., Clelland, B. W., Hockman, D. J., Kujat-Choy, S. L., Mewhort, H. E., and Schultz, M. C. (2010). Replication stress checkpoint signaling controls tRNA gene transcription. Nat. Struct. Mol. Biol. 17, 976-981.

Nyberg, K. A., Michelson, R. J., Putnam, C. W., and Weinert, T A. (2002). Toward maintaining the genome: DNA damage and replication checkpoints. Annu. Rev. Genet. 36, 617-656.

O'Neill, B. M., Szyjka, S. J., Lis, E. T., Bailey, A. O., Yates, J. R. 3rd., Aparicio, O. M., et al. (2007). Pph3-Psy2 is a phosphatase complex required for Rad53 dephosphorylation and replication fork restart during recovery from DNA damage. Proc. Natl. Acad. Sci. U.S.A. 104, 9290-9295.

Osborn, A. J., and Elledge, S. J. (2003). $\mathrm{Mrcl}$ is a replication fork component whose phosphorylation in response to DNA replication stress activates Rad53. Genes Dev. 17, 1755-1767.

Osborn, A. J., Elledge, S. J., and Zou, L. (2002). Checking on the fork: the DNA-replication stress-response pathway. Trends Cell Biol. 12, 509-516.

Paciotti, V., Clerici, M., Scotti, M. Lucchini, G., and Longhese, M. P. (2001). Characterization of mec1 kinase-deficient mutants and of new hypomorphic mecl alleles impairing subsets of the DNA damage response pathway. Mol. Cell. Biol. 21, 3913-3925.

Palou, G., Palou, R., Guerra-Moreno, A., Duch, A., Travesa, A., and Quintana, D. G. (2010). Cyclin regulation by the $\mathrm{s}$ phase checkpoint. J. Biol. Chem. 285, 26431-26440.

Paulovich, A. G., and Hartwell, L. H. (1995). A checkpoint regulates the rate of progression through $S$ phase in $S$. cerevisiae in response to DNA damage. Cell 82, 841-847.

Pellicioli, A., and Foiani, M. (2005). Signal transduction: how rad53 kinase is activated. Curr. Biol. 15, R769-R771.

Pellicioli, A., Lucca, C., Liberi, G., Marini, F., Lopes, M., Plevani, P., et al. (1999). Activation of Rad53 kinase in response to DNA damage and its effect in modulating phosphorylation of the lagging strand DNA polymerase. EMBO J. 18 6561-6572.

Peschiaroli, A., Dorrello, N. V., Guardavaccaro, D., Venere, M. Halazonetis, T., Sherman, N. E., et al. (2006). SCFbetaTrCPmediated degradation of Claspin regulates recovery from the DNA replication checkpoint response Mol. Cell 23, 319-329.

Postow, L., Crisona, N. J., Peter, B. J. Hardy, C. D., and Cozzarelli, N. R. (2001a). Topological challenges to DNA replication: conformations at the fork. Proc. Natl. Acad. Sci. U.S.A 98, 8219-8226.

Postow, L., Ullsperger, C., Keller, R. W., Bustamante, C., Vologodskii, A. V., and Cozzarelli, N. R. (2001b) Positive torsional strain causes the formation of a four-way junction at replication forks. J. Biol. Chem. 276, 2790-2796.

Pursell, Z. F., Isoz, I., Lundstrom, E. B., Johansson, E., and Kunkel, T. A. (2007). Yeast DNA polymerase epsilon participates in leadingstrand DNA replication. Science $317,127-130$

Putnam, C. D., Jaehnig, E. J., and Kolodner, R. D. (2009). Perspectives on the DNA damage and replication checkpoint responses in Saccharomyces cerevisiae. DNA Repair (Amst.) 8, 974-982.

Raghuraman, M. K., Winzeler, E. A., Collingwood, D., Hunt, S., Wodicka, L., Conway, A., et al.
(2001). Replication dynamics of the yeast genome. Science 294, 115-121.

Randell, J. C., Fan, A., Chan, C., Francis, L. I., Heller, R. C., Galani, K., et al. (2010). Mecl is one of multiple kinases that prime the $\mathrm{Mcm} 2-$ 7 helicase for phosphorylation by Cdc7. Mol. Cell 40, 353-363.

Raveendranathan, M., Chattopadhyay, S., Bolon, Y. T., Haworth, J., Clarke, D. J., and Bielinsky, A. K. (2006). Genome-wide replication profiles of S-phase checkpoint mutants reveal fragile sites in yeast. $E M B O \mathrm{~J} .25$, 3627-3639.

Ray Chaudhuri, A., Hashimoto, Y., Herrador, R., Neelsen, K. J., Fachinetti, D., Bermejo, R., et al. (2012). Topoisomerase I poisoning results in PARP-mediated replication fork reversal. Nat. Struct. Mol. Biol. 19, 417-423.

Rhind, N., and Russell, P. (1998). Mitotic DNA damage and replication checkpoints in yeast. Curr. Opin. Cell Biol. 10, 749-758.

Rodriguez, J., and Tsukiyama, T. (2013). ATR-like kinase Mecl facilitates both chromatin accessibility at DNA replication forks and replication fork progression during replication stress. Genes Dev. 27, 74-86.

Rowley, R., Subramani, S., and Young, P. G. (1992). Checkpoint controls in Schizosaccharomyces pombe: $\mathrm{rad} 1$. ЕМBO J. 11, 1335-1342.

Santocanale, C., and Diffley, J. F. (1998). A Mec1- and Rad53dependent checkpoint controls late-firing origins of DNA replication. Nature 395, 615-618.

Savitsky, K., Bar-Shira, A., Gilad, S., Rotman, G., Ziv, Y., Vanagaite, L., et al. (1995). A single ataxia telangiectasia gene with a product similar to PI-3 kinase. Science 268, 1749-1753.

Segurado, M., and Diffley, J. F. (2008). Separate roles for the DNA damage checkpoint protein kinases in stabilizing DNA replication forks. Genes Dev. 22, 1816-1827.

Segurado, M., and Tercero, J. A. (2009). The S-phase checkpoint: targeting the replication fork. Biol. Cell 101, 617-627.

Shen, C., Lancaster, C. S., Shi, B., Guo, H., Thimmaiah, P., and Bjornsti, M. A. (2007). TOR signaling is a determinant of cell survival in response to DNA damage. Mol. Cell Biol. 27, 7007-7017.

Shirahige, K., Hori, Y., Shiraishi, K., Yamashita, M., Takahashi, K., Obuse, C., et al. (1998). Regulation of DNA-replication origins during cell-cycle progression. Nature 395, 618-621. 
Smolka, M. B., Albuquerque, C. P., Chen, S. H., and Zhou, H. (2007). Proteome-wide identification of in vivo targets of DNA damage checkpoint kinases. Proc. Natl. Acad. Sci. U.S.A. 104, 10364-10369.

Smolka, M. B., Bastos De Oliveira, F. M., Harris, M. R., and De Bruin, R. A. (2012). The checkpoint transcriptional response: make sure to turn it off once you are satisfied. Cell Cycle 11, 3166-3174.

Sogo, J. M., Lopes, M., and Foiani, M. (2002). Fork reversal and ssDNA accumulation at stalled replication forks owing to checkpoint defects. Science 297, 599-602.

Stokes, M. P., Van Hatten, R., Lindsay, H. D., and Michael, W. M. (2002). DNA replication is required for the checkpoint response to damaged DNA in Xenopus egg extracts. J. Cell Biol. 158, 863-872.

Szyjka, S. J., Aparicio, J. G., Viggiani, C. J., Knott, S., Xu, W., Tavare, S., et al. (2008). Rad53 regulates replication fork restart after DNA damage in Saccharomyces cerevisiae. Genes Dev. 22, 1906-1920.

Szyjka, S. J., Viggiani, C. J., and Aparicio, O. M. (2005). Mrcl is required for normal progression of replication forks throughout chromatin in S. cerevisiae. Mol. Cell 19, 691-697.

Tanaka, K., and Russell, P. (2001). Mrcl channels the DNA replication arrest signal to checkpoint kinase Cds1. Nat. Cell Biol. 3, 966-972.

Tercero, J. A., and Diffley, J. F. (2001). Regulation of DNA replication fork progression through damaged DNA by the Mec1/Rad53 checkpoint. Nature 412, 553-557.
Tercero, J. A., Longhese, M. P., and Diffley, J. F. (2003). A central role for DNA replication forks in checkpoint activation and response. Mol. Cell 11, 1323-1336.

Tourriere, H., Versini, G., CordonPreciado, V., Alabert, C., and Pasero, P. (2005). Mrcl and Tofl promote replication fork progression and recovery independently of Rad53. Mol. Cell 19, 699-706.

Travesa, A., Duch, A., and Quintana, D. G. (2008). Distinct phosphatases mediate the deactivation of the DNA damage checkpoint kinase Rad53. J. Biol. Chem. 283 17123-17130.

Travesa, A., Kuo, D., De Bruin, R. A. Kalashnikova, T. I., Guaderrama, M., Thai, K., et al. (2012). DNA replication stress differentially regulates G1/S genes via Rad53dependent inactivation of $\mathrm{Nrml}$. EMBO J. 31, 1811-1822.

Waga, S., and Stillman, B. (1998). The DNA replication fork in eukaryotic cells. Annu. Rev. Biochem. 67, 721-751.

Wang, J. C. (2002). Cellular roles of DNA topoisomerases: a molecular perspective. Nat. Rev. Mol. Cell Biol. 3, 430-440.

Weinert, T. A. (1992). Dual cell cycle checkpoints sensitive to chromosome replication and DNA damage in the budding yeast Saccharomyces cerevisiae. Radiat. Res. 132, 141-143.

Weinert, T. A., Kiser, G. L., and Hartwell, L. H. (1994). Mitotic checkpoint genes in budding yeast and the dependence of mitosis on DNA replication and repair. Genes Dev. 8, 652-665.

Yao, R., Zhang, Z., An, X., Bucci, B., Perlstein, D. L., Stubbe, J., et al. (2003). Subcellular localization of yeast ribonucleotide reductase regulated by the DNA replication and damage checkpoint pathways. Proc. Natl. Acad. Sci. U.S.A. 100 , 6628-6633.

You, Z., Kong, L., and Newport, J. (2002). The role of single-stranded DNA and polymerase alpha in establishing the ATR, Hus1 DNA replication checkpoint. J. Biol. Chem. 277, 27088-27093.

Zaim, J., Speina, E., and Kierzek, A M. (2005). Identification of new genes regulated by the Crtl transcription factor, an effector of the DNA damage checkpoint pathway in Saccharomyces cerevisiae. J. Biol. Chem. 280, 28-37.

Zegerman, P., and Diffley, J. F. (2009). DNA replication as a target of the DNA damage checkpoint. DNA Repair (Amst.) 8, 1077-1088.

Zegerman, P., and Diffley, J. F. (2010) Checkpoint-dependent inhibition of DNA replication initiation by Sld3 and Dbf4 phosphorylation. Nature 467, 474-478.

Zhang, Y. W., Otterness, D. M., Chiang, G. G., Xie, W., Liu, Y. C., Mercurio, F., et al. (2005). Genotoxic stress targets human Chk1 for degradation by the ubiquitin-proteasome pathway. Mol. Cell 19, 607-618.

Zhao, X., Chabes, A., Domkin, V. Thelander, L., and Rothstein, R. (2001). The ribonucleotide reductase inhibitor Smll is a new target of the Mec1/Rad53 kinase cascade during growth and in response to DNA damage. EMBO J. 20, 3544-3553.

Zhao, X., Muller, E. G., and Rothstein, R. (1998). A suppressor of two essential checkpoint genes identifies a novel protein that negatively affects dNTP pools. Mol. Cell 2, 329-340.

Zhao, X., and Rothstein, R. (2002). The Dun1 checkpoint kinase phosphorylates and regulates the ribonucleotide reductase inhibitor Sml1. Proc. Natl. Acad. Sci. U.S.A. 99, 3746-3751.

Zhou, Z., and Elledge, S. J. (1993). DUN1 encodes a protein kinase that controls the DNA damage response in yeast. Cell 75, 1119-1127.

Zou, L., and Elledge, S. J. (2003). Sensing DNA damage through ATRIP recognition of RPA-ssDNA complexes. Science 300, 1542-1548.

Conflict of Interest Statement: The authors declare that the research was conducted in the absence of any commercial or financial relationships that could be construed as a potential conflict of interest.

Received: 31 January 2013; paper pending published: 11 February 2013; accepted: 18 February 2013; published online: 13 March 2013.

Citation: Jossen R and Bermejo R (2013) The DNA damage checkpoint response to replication stress: A Game of Forks. Front. Genet. 4:26. doi: 10.3389/fgene. 2013.00026

This article was submitted to Frontiers in Cancer Genetics, a specialty of Frontiers in Genetics.

Copyright (c) 2013 Jossen and Bermejo. This is an open-access article distributed under the terms of the Creative Commons Attribution License, which permits use, distribution and reproduction in other forums, provided the original authors and source are credited and subject to any copyright notices concerning any third-party graphics etc. 